\title{
Technology Deployment Annual Report 2010
}

December 2010

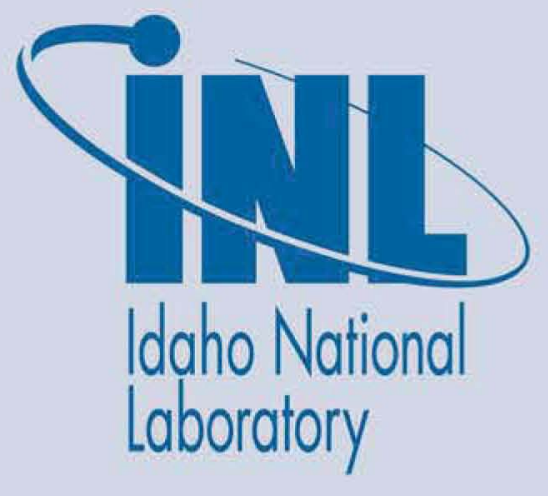

The INL is a U.S. Department of Energy National Laboratory operated by Battelle Energy Alliance 
INL/EXT-10-20698

\title{
Technology Deployment Annual Report 2010
}

December 2010

\author{
Idaho National Laboratory \\ Idaho Falls, Idaho 83415
}

http://www.inl.gov

Prepared for the

U.S. Department of Energy

Office of Nuclear Energy

Under DOE Idaho Operations Office

Contract DE-AC07-05ID14517 


\section{Technology Deployment}

Annual Report 2010

December
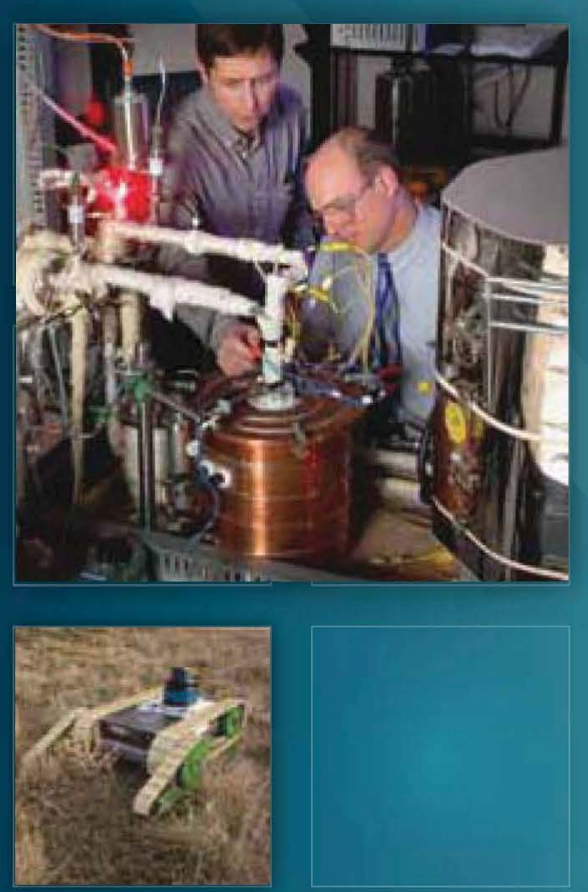
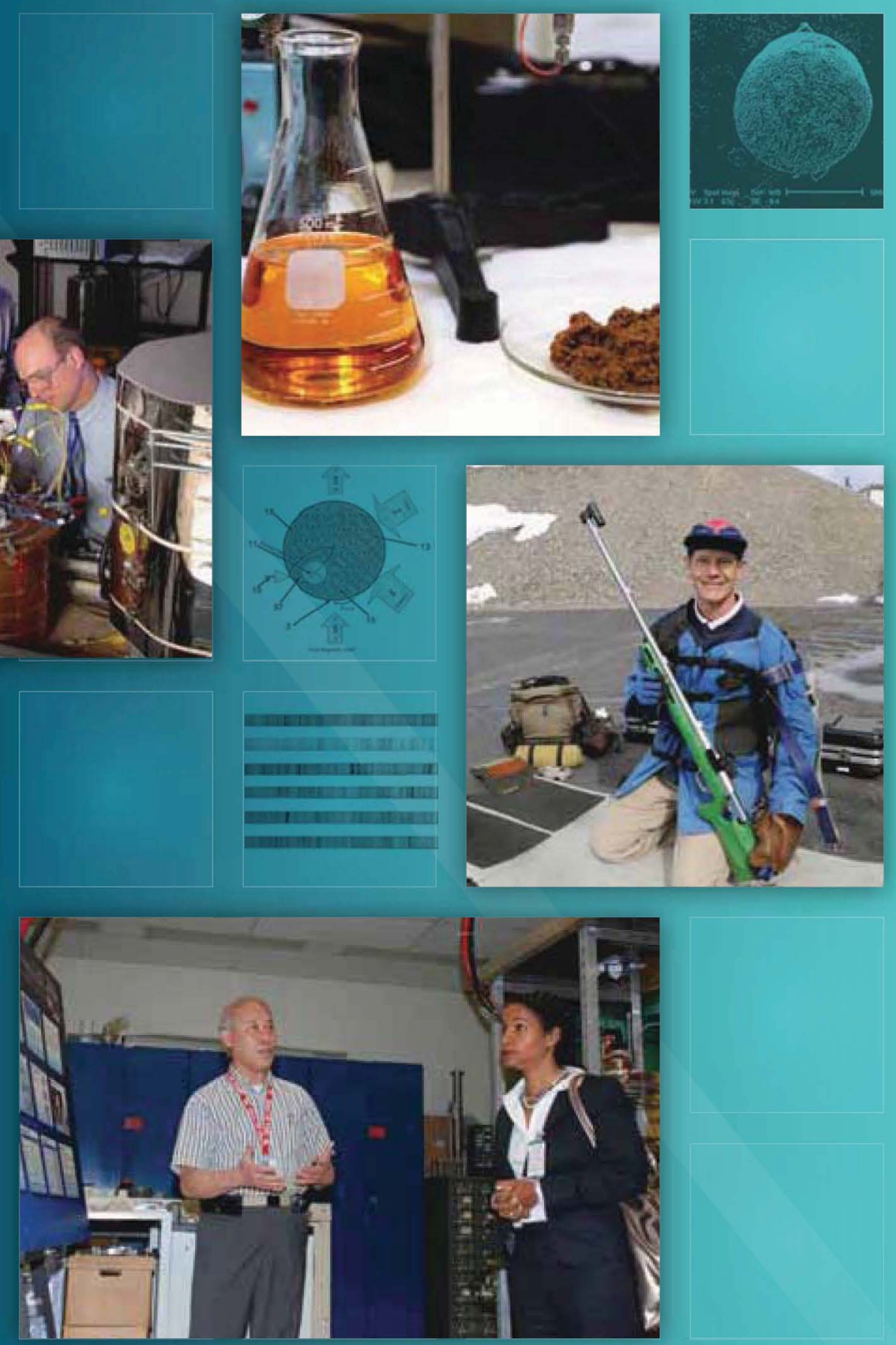
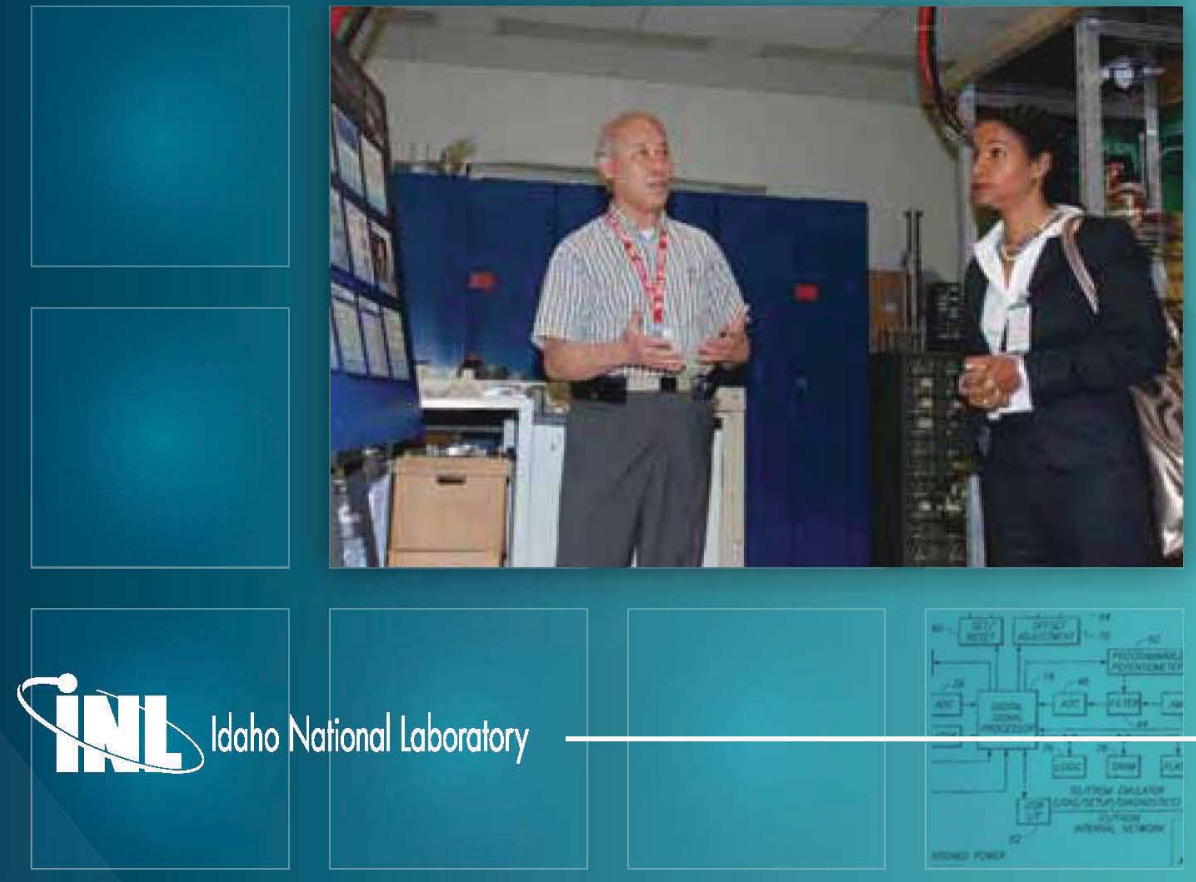

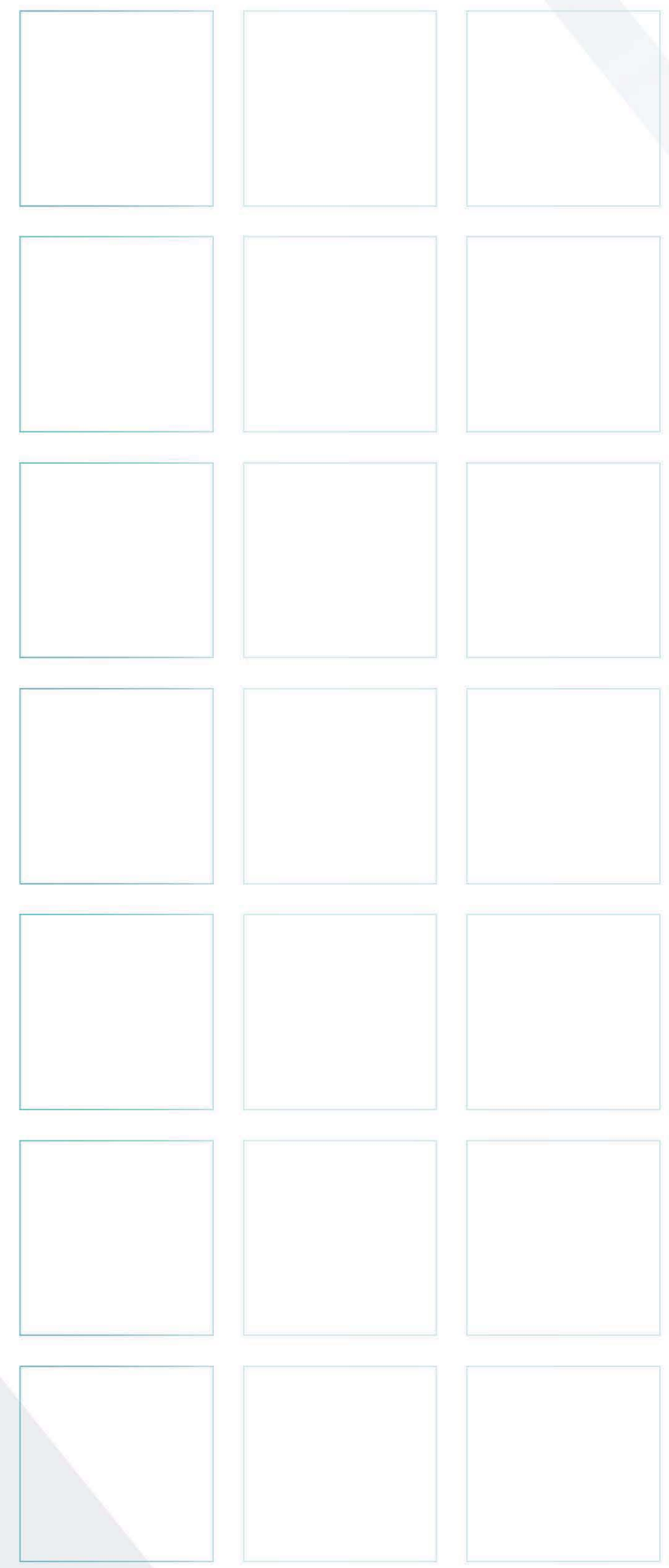


\section{Contents}

From the Laboratory Director.

2

From the Technology Deployment Director.........................................................

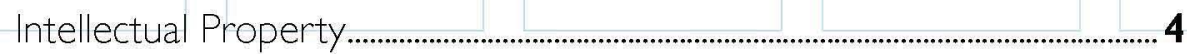

Granted Copyrights ................................................................................. 16

Royalties.

17

License Agreements.

17

Cooperative Research and Development Agreements.

22

Work For Others

25

Technology-Based Economic Development Highlights

27

Technical Assistance Program.

29

Other Key Events and Successes for FY2010

30
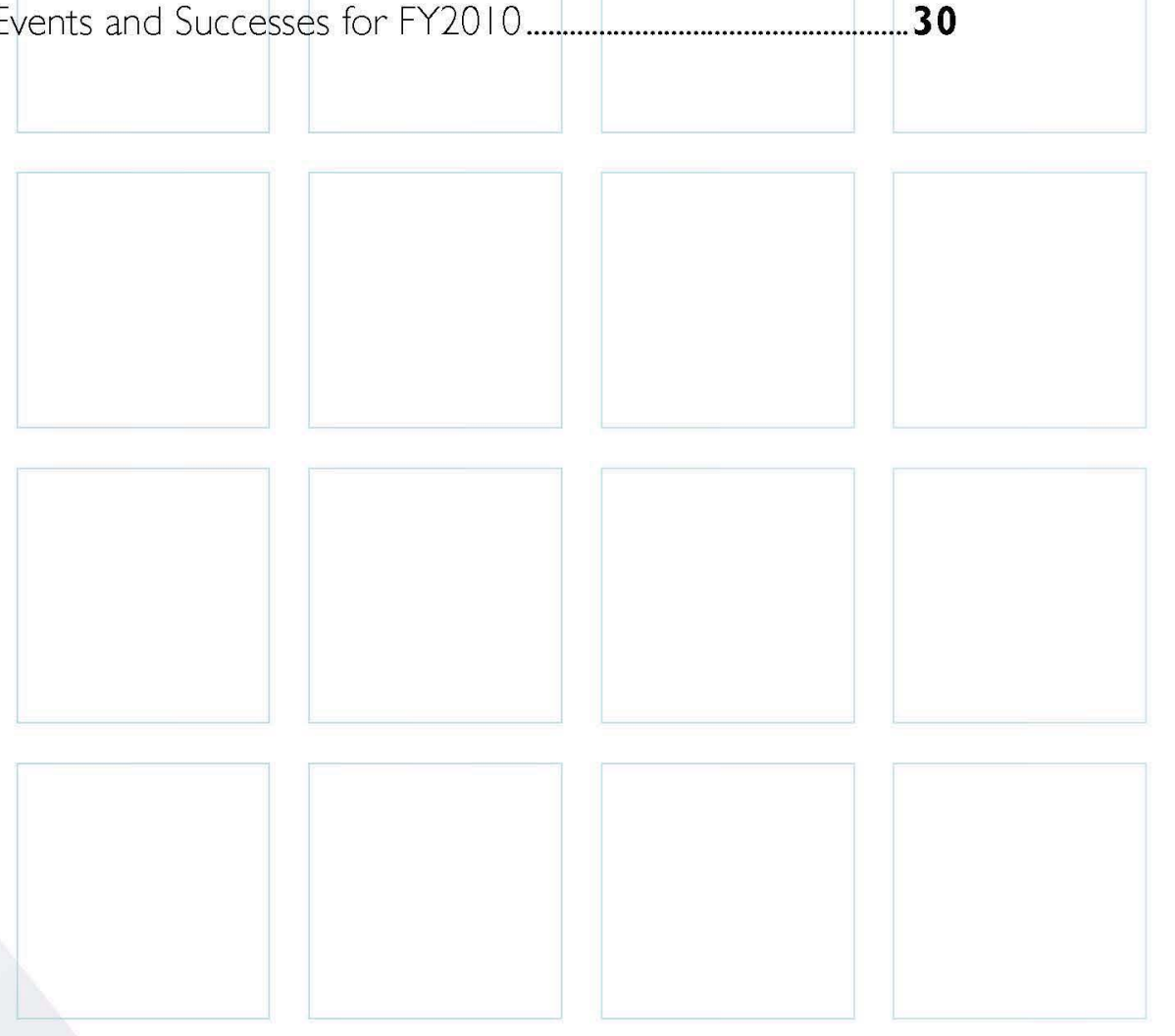


\section{From the Laboratory Director}

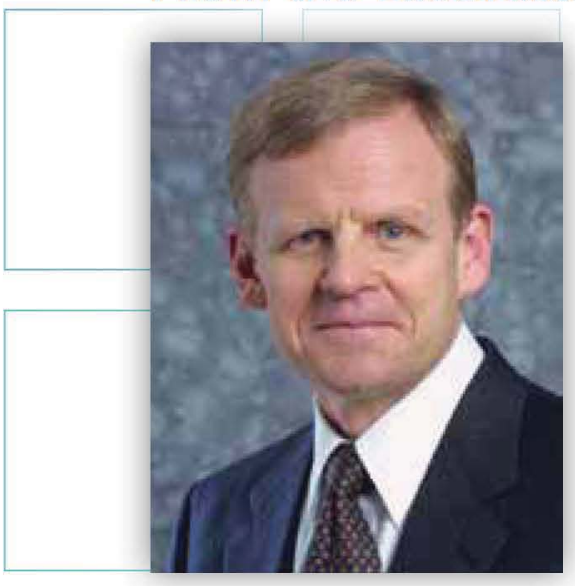

$1 \begin{aligned} & \text { omorrow's economic future } \\ & \text { depends on today's innova- }\end{aligned}$ tive research, development and technology deployment. INL is meeting the needs of America's ongoing economic challenges by increasing research capabilities, constructing new facilities, and building relationships with industry to license and deploy technologies and discoveries originating with INL researchers. Specifically, INL's spirit of innovation is providing leadership in the advancement of nuclear energy, dean and alternative energy resource initiatives and national and homeland security capabilities.

During Battelle Energy Alliance's six-year tenure managing the INL contract, an exceptional record of progress has been achieved in patented inventions, scientific discoveries, software development, technologies deployed or licensed, Cooperative Research and Development Agreements (CRADA), contract work under our Work for Others (WFO) program and technology-based economic development.

Since 2005, INL has attracted 307 projects representing nearly $\$ 1.8$ billion in our contracted WFO programs (other than DOE) and nearly $\$ 190$ million through 113 CRADAs. INL earned more than $\$ 6.5$ million in royalties from signing nearly 500 technology licenses, generating 550 Invention Disclosure Records (IDRs) and filing nearly 300 patent applications, including nearly 250 patents being issued to INL researchers during this time.

BEA reports a highly productive year in fiscal year 2010, in which INL professionals delivered nearly $\$ 200$ million dollars of research and development work to customers in 42 federal and non-federal contract agreements and 10 CRADAs worth more than $\$ 19$ million. With royalty earnings at more than $\$ 6.5$ million during the past six years, INL added another million dollars during 2010. The signed licenses for the year totaled 39 , including 10 patent licenses and 29 copyright licenses or license options. The number of IDRs increased to 84 this year, forecasting more vital intellectual property deployment opportunities for the near future. There were 53 patents issued, with another 54 patent applications filed, covering inventions resulting from our researchers' efforts.

Significant work and licensing activity revolve around INL's principle mission - nuclear energy research. Nearly two dozen licenses were negotiated and signed for INL's RELAP code series to aid energy systems companies, universities, national laboratories and others, both domestically and internationally, in safeguarding and managing nuclear reactor operations and research. The agreements advance

\section{"INL's spirit of innovation is providing leadership in the advancement of nuclear energy, clean and alternative energy resource initiatives and national and homeland security capabilities." \\ John Grossenbacher \\ Director, Idaho National Laboratory}

the technology to develop and deploy new reactors and fuel designs for the future. All of this is advancing the nuclear renaissance that is emerging around the globe.

INL has made a significant impact on the establishment of a sustainable entrepreneurial ecosystem in the regional economy, with an impact of $\$ 3.5$ billion, according to the 2010 economic impact study conducted by Boise State University. INL researchers and staff made time for important contributions in the region by sharing their technical skills with community organizations and technologybased businesses to advance entrepreneurial efforts and bring new jobs to the region. This included encouraging the high technology business sector by leveraging regional partnerships in Idaho and the region, positioning large portions of the $\$ 4.5$ million education and economic development grants, creating awareness of federal assistance opportunities, providing educational opportunities to students, and sponsoring workshops that help emerging entrepreneurs obtain needed business skills.

While statistics are important indicators of performance, they tell only part of the story. INL has earned 44 international R\&D 100 awards since 1986. In 2010, the Supercritical Solid Catalyst (SSC) technology research team won the R\&D 100, a Federal Laboratory Consortium Far West Award, runner up in the Wall Street Technology Innovation Awards, finalist in the Platts Global Energy Award and the regional Idaho Innovation Award, posting an international recognition record unequaled at INL. In addition, SSC team co-leader, Dr. Robert V. Fox, was a finalist in R\&D Magazine's Scientist of the Year competition and won the Idaho Innovator of the Year Award.

This summary records considerable achievements that demonstrate INL's pride in our talented employees, innovative research and the exceptional efficiency of our laboratory in meeting INL's mission of ensuring the nation's energy security with safe, competitive and sustainable energy systems and unique national and homeland security capabilities.

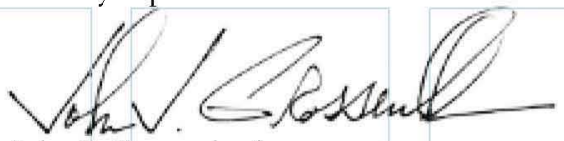

John J. Grossenbacher

Director, Idaho National Laboratory 


\section{From the Technology Deployment Director}

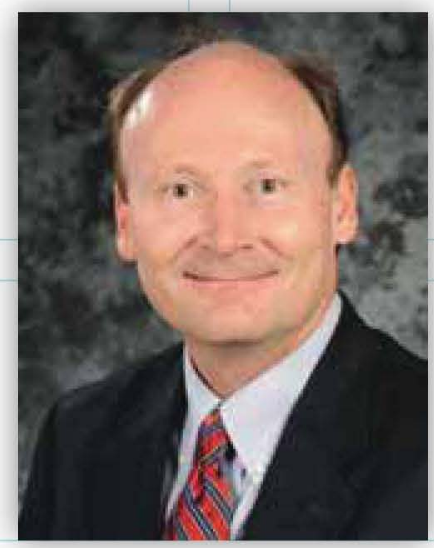

$\mathrm{A}_{\text {of the INL team, I am proud }}^{\text {sone the newest member }}$ Aof the INL team, I am proud to have joined an organization with such a profound mission, strong spirit of innovation, and dedication to outcome. The successes cataloged in this report reflect a culmination of inspiring efforts that further demonstrates the value of your hard work and talent.

It's a pleasure to introduce myself and the 2010 Technology Deployment Annual Report. I have been warmly welcomed to Idaho and the Idaho National Laboratory. I'm excited to work with the many talented individuals that have contributed to Technology Deployment's performance this past year.

In the pages that follow, you will learn about Technology Deployment's continuing efforts to Increase its Value to INL's Mission, Improve Operations, and Implement a Performance-Based Culture. The transformation that began in 2009 under Brent Stacey's visionary leadership has continued.

Success in deploying new technologies requires a team effort. Technology Deployment had a productive year in 2010, and is on course for an even more successful future as together we work to enhance INL's deployment efforts. With the help of many - scientists, engineers, managers, investors, legislators, innovators, community supporters, and contributors across the deployment spectrum, we will make an impact on the challenge of accelerating the pace of change in energy technologies to satisfy the complex energy needs of our nation.

We appreciate the support and encouragement received during 2010 from private and government sponsors, agencies, licensees, users and partners. We regularly learn from our counterparts at the other DOE laboratories and acknowledge the ongoing support of the Department of Energy Idaho Operations Office.
"Success in deploying new technologies requires a team effort. Technology Deployment had a productive year in 2010, and is on course for an even more successful future as together we work to enhance INL's deployment efforts."

\section{Steven McMaster, Director, Technology Deployment}

This year much has been accomplished in strengthening Technology Deployment. Our focus has been on setting strategic goals, teaming with INL's three research directorates, improving communications, enhancing awards and recognition programs, and improving the regional entrepreneurial climate through our Technology-Based Economic Development program. We accomplished nearly all we set out to do during 2010, and we are excited to continue improving our performance during the coming year.

During 2010, it has been satisfying to have INL's innovators and innovations receive national and international recognition for their accomplishments. Look for more in the report about the record breaking year of external awards and recognition.

This report catalogs the achievements of INL inventors during this transformational year. Much "behind the scenes" work goes into intellectual property creation, management and commercialization by not only inventors but research managers, legal staff, and technology transfer professionals. The process undeniably begins and cannot be sustained without our scientific and technical staff. As we continue to grow our collaborative partnerships with universities, industry and government, I believe we are setting the stage for new invention opportunities and discoveries that will be a factor in INL's and America's growth and prosperity for years to come.

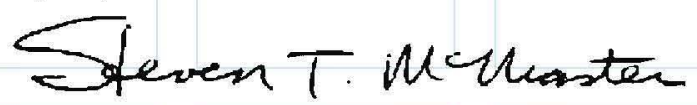

Steven T. McMaster

Director, Technology Deployment 


\section{Intellectual Property}
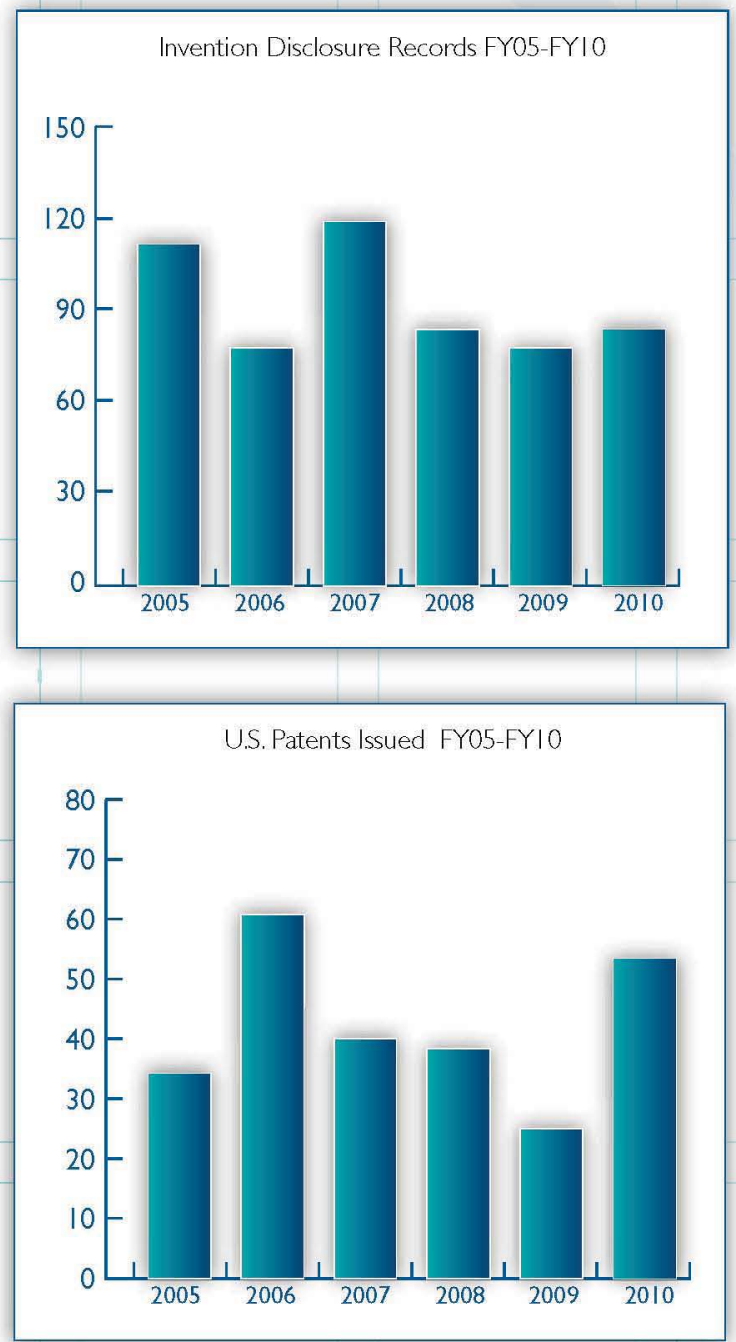

Idaho National Laboratory's (INL) portfolio of Intellectual Property (IP) is composed of requested and granted copyrights, filed patent applications and issued patents. These provide a basis for interacting with national laboratories and federal agencies, commercial enterprises academia and other parties. Accumulated IP portfolios are one key measure of the institution's ability to do creative, meaningful research.

Technology Deployment works closely with researchers and management to identify and pursue technology commercialization and business development opportunities. In 2010, 84 Invention Disclosures Records (IDRs) were submitted to Battelle Energy Alliance (BEA) by INL inventors and 53 U.S. patents were issued either to INL or the Department of Energy based on the inventions of INL scientists and researchers.

During the past six year, INL researchers have generated 550 IDRs, filed nearly 300 patent applications and received nearly 250 issued patents.

BEA has the right under its contract, subject to some exceptions, to take title to inventions and seek patent protection. The decision of whether or not to take title and seek patent protection is based on market and technical assessments of the technology and its subsequent programmatic value. Market assessments are performed and a recommendation is presented to a committee comprised of department or project managers, assistant lab director or designee, market analysts, commercialization managers, and patent attorneys. These recommendations are presented before the team, where a final decision is made to elect or decline the technology for patent protection. Generally, if the invention is judged as commercially valuable, crucial to a primary mission, or valuable in terms of motivating further research funding, it is elected. If BEA decides to decline title, DOE decides on whether to seek patent protection in its own name. If DOE decides not to seek patent protection, the inventor(s) may petition to have title waived to them by DOE with the expectation that they will pursue patent protection using their own resources.

A brief description of each patent issued during FY2010 based on INL inventions is provided on the following pages.

\section{Material Forming Tool and Method for Forming a Material}

Charles Tolle, Denis Clark, Herschel Smartt and Karen Miller were issued a patent for a method using friction stir to mechanically forge a new class of alloys in a precisely controlled, graded manner. This process produces significantly different microstructures than the ones produced by existing casting processes. It also can produce graded microstructures that could, for example, be bullet resistant on one side and have good structural properties on the opposite side.

Patent Number: 7,597,236

Date Issued: Oct. 6, 2009 


\section{Process for Radioisotope Recovery and System for} Implementing Same

David Meikrantz, Terry Todd, Troy Tranter and Philip Horwitz were issued a patent for recovering daughter isotopes from a radioisotope mixture for reuse. The method uses several steps involving a parent isotope in an organic phase, then an annular centrifugal contactor for separation, and finally an aqueous phase to extract at least one daughter isotope into the aqueous phase.

Patent Number: 7,597,862

Date Issued: Oct. 6, 2009

\section{Flow through In-Situ Reactors with Suction Lysimeter Sampling Capability and Methods of Use}

Corey Radtke, Brad Blackwelder and Joel Hubbell were issued a patent for an in-situ reactor for the use in a geological strata to remediate contaminated soil. This invention is a small mixing device for in-situ mixing to improve the flow up through the length of the reactor. The advantage is that the contaminant is rapidly mixed with the treatment instead of relying on diffusion.

Patent Number: 7,617,742

Date Issued: Nov. 17, 2009

\section{Robotic Intelligence Kernel}

David Bruemmer was issued a patent for a system controller that executes a robot intelligence kernel (RIK) multi-level architecture for defining conduct modules that blend an adaptive interaction between predefined decision functions and the robot behaviors. These robotic behavior capabilities are analogous to that of a highly trained police dog.

Patent Number: 7,620,477

Date Issued: Nov. 17, 2009
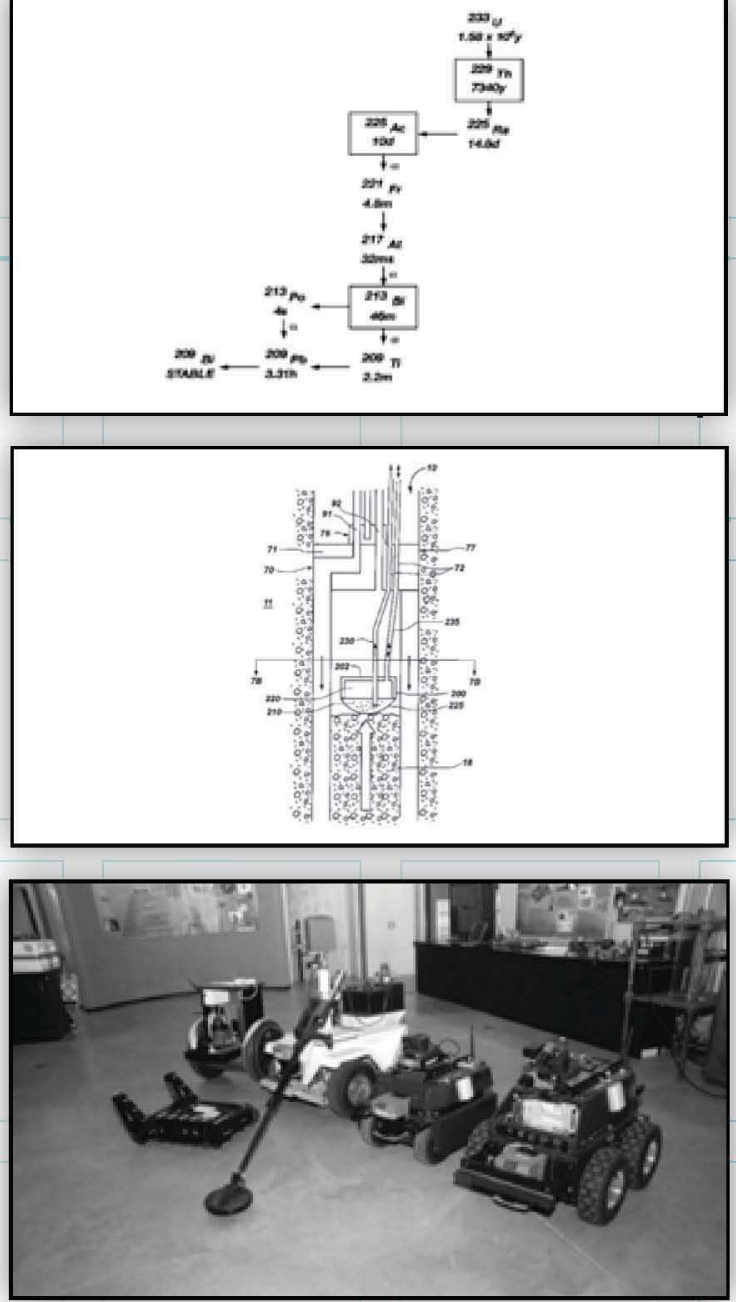

Impedance Estimation Methods, Modeling Methods, Articles of Manufacture, Impedance Modeling Devices, and Estimated Impedance Monitoring Systems

John Richardson (retiree) was issued a patent for an impedance estimation method that uses three or more probes to perform non-destructive evaluation of surfaces

Patent Number: 7,620,507

Date Issued: Nov. 17, 2009
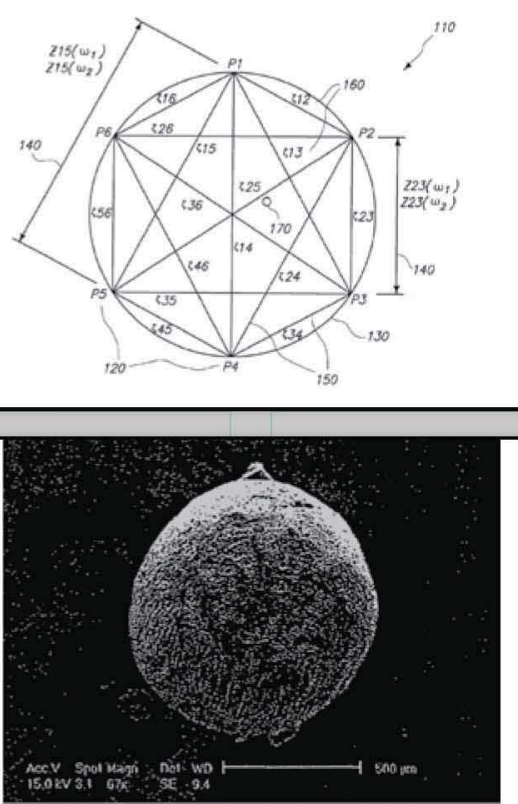

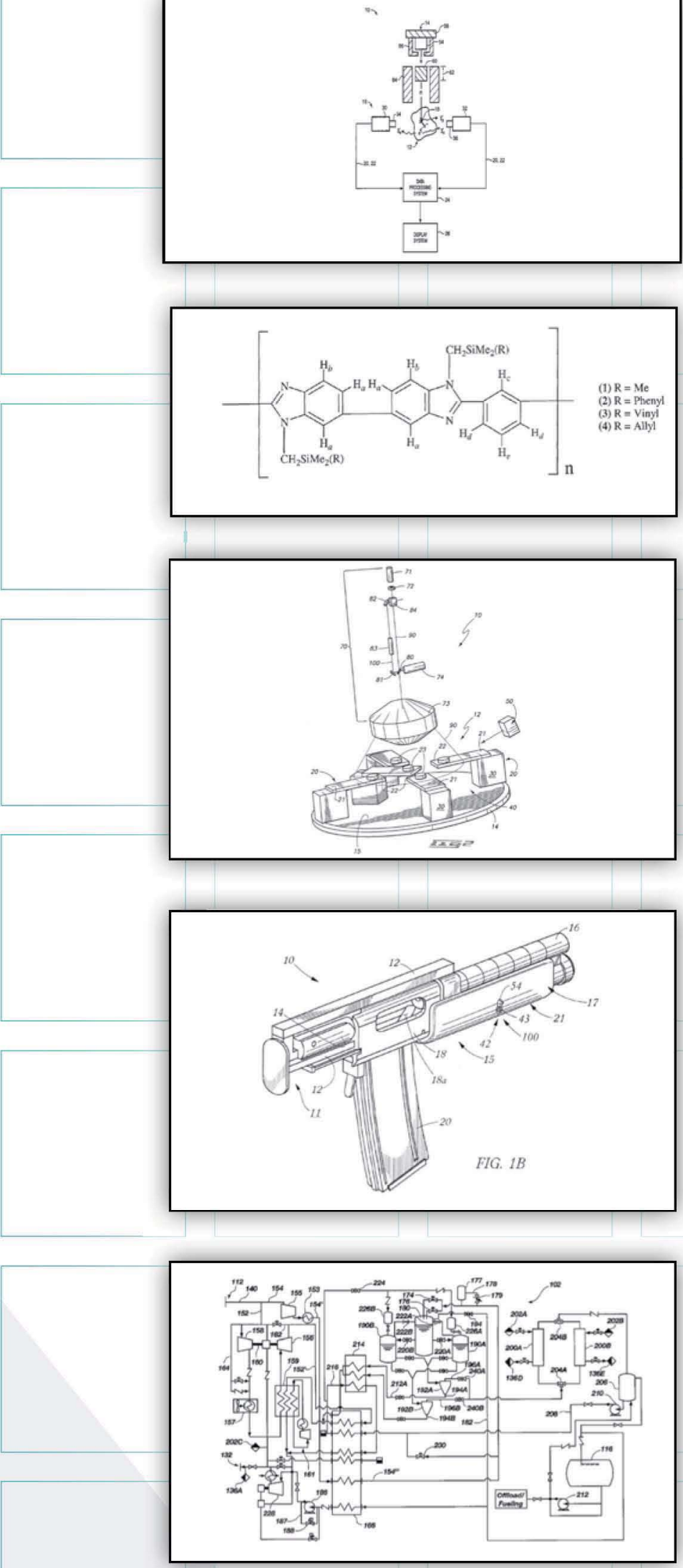

\section{Method for On-Line Evaluation of Materials Using Prompt Gamma Ray Analysis}

Doug Akers was issued a patent for a method for evaluating a material specimen by mounting a neutron source and a detector adjacent to the material specimen and bombarding the material specimen with neutrons from the neutron source to create prompt gamma rays within the material specimen. The system permits positron annihilation analysis as some of the prompt gamma rays are emitted from the material specimen, some of the prompt gamma rays form positrons within the material specimen by pairs. Positron annihilation data is collected by detecting annihilation gamma rays from the annihilation of a positron, then stored on a data storage system for later retrieval and processing.

Patent Number: 7,630,469

Date Issued: Dec. 8, 2009

\section{Polymeric Media Comprising Polybenzimidazoles} $\mathrm{N}$-Substituted with Organic-Inorganic Hybrid Moiety

John Klaehn, Eric Peterson, Alan Wertsching, Chris Orme, Thomas Luther and Michael Jones were issued a patent for a polybenzimidazole (PBI) compound that includes imidazole nitrogens, at least a portion of which are substituted with an organic-inorganic hybrid moiety, which may include separation membranes. The organic-inorganic hybrid may be an organosilane, for example, (R)Me2SiCH2where $\mathrm{R}$ is methyl, phenyl, vinyl, or allyl. This discovery permits forming this specific high temperature polymer into complex shapes ranging from flat sheets to cylinders.

Patent Number: 7,632,898

Date Issued: Dec. 15, 2009

\section{Sensor Apparatus}

Vance Deason and Ken Telschow were issued a patent for a method for read out of micro sensor arrays used to detect chemicals of interest in a broad range of scientific fields. The Imaging Ultrasonic Microscope directly images all the micro-sensors simultaneously and accurately, negating cross-talk across wiring channels caused by an increase in the number of arrays on micro-sensors.

Patent Number: 7,635,942

Date Issued: Dec. 22, 2009

\section{Forwardly-Placed Firearm Fire Control Assembly}

Steve Frickey was issued a patent for a design concept that places the fire control group for a firearm forward into the position, that is usually occupied by the supporting hand enabling fire control manipulation by that hand. This breaching system design includes a triggering, fire selection and safety mechanism.

Patent Number 7,634,959

Date Issued: Dec. 22, 2009

Apparatus for the Liquefaction of a Gas and Methods Relating to Same

Terry Turner, Bruce Wilding and Michael McKellar were issued a patent for the design of small-scale liquefaction plants for an efficient configuration that works in a variety of places that do not have the optimal natural gas services, including insufficient compression (horsepower). This new configuration splits the incoming supply gas into two streams that can enter the plant at different pressures and flow rates, resulting in greater flexibility in controlling internal pressures, refrigeration demands, and maximizing yields using minimum flows.

Patent Number 7,637,122

Date Issued: Dec. 29, 2009 


\section{Image Change Detection Systems, Methods, and Articles of Manufacture}

James Jones, Gordon Lassahn, and Greg Lancaster were issued a patent relating to image change detection methods which identify differences between pluralities of images. The method includes loading a source image and a target image into memory of a computer, constructing source and target edge images from the source and target images to enable processing of multiband images, displaying the source and target images on a display device of the computer, aligning the source and target edge images, switching displays of the source image and the target image on the display device, and enabling identification of differences between the source image and the target image.

Patent Number: 7,643,703

Date Issued: Jan. 5, 2010

\section{Tire Deflation Device}

Stacey Barker was issued a patent for a multiple bore tire deflation device, a unique keeper design which solves legal problems with using a grommet to attach the spike. These retractable spike strips are used by law enforcement to stop suspects by deflating the tires of a vehicle in a controlled fashion.

Patent Number: 7,641,417

Date Issued: Jan. 5, 2010

\section{Methods, Systems and Devices for Detecting} and Locating Ferromagnetic Objects

Lyle Roybal, Dale Kotter, David Rohrbaugh and David Spencer invented a security system for detecting ferromagnetic objects that may be passing through a security screening system. This system has the ability to provide much better detection of weapons, including the ability to distinguish between types of weapons.

Patent Number: 7,652,572

Date Issued: Jan. 26, 2010

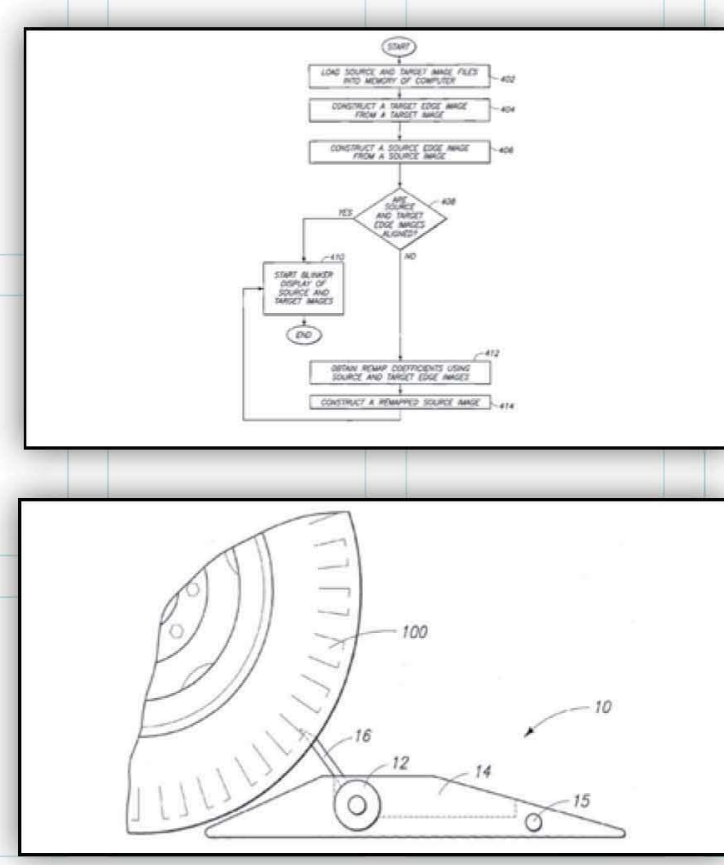

\section{Soil Separator and Sampler and Method of Sampling}

Barry O'Brien and Paul Ritter created a fluidized bed soil sampler with a vacuum for drawing air through the fluidized bed to separate the particulate matter thus facilitating the detection of asbestos. The process could be used at several asbestos-contaminated sites. Depending on the removal efficiency, it could easily be scaled up to remove asbestos contamination from the soil.The process requires less manpower and time, plus it reduces carryover of unwanted material.

Patent Number: 7,662,217

Date Issued: Feb. 16, 2010

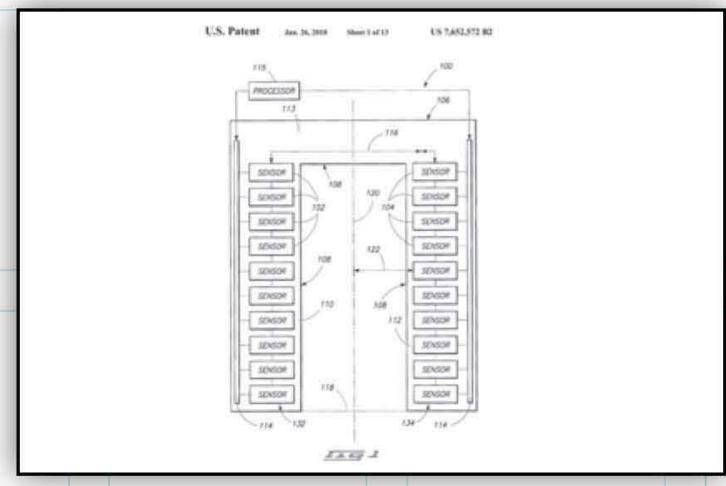

\section{Firearm Trigger Assembly}

David Crandall and Richard Watson designed a trigger that is mounted on the fore-stock of a firearm that is attached under the barrel of another firearm. This reduces overall firearm length and allows firing of either weapon without changing the position of the hands. In a combat situation, this difference can mean the difference between life and death.

Patent Number: 7,661,220

Date Issued: Feb. 16, 2010

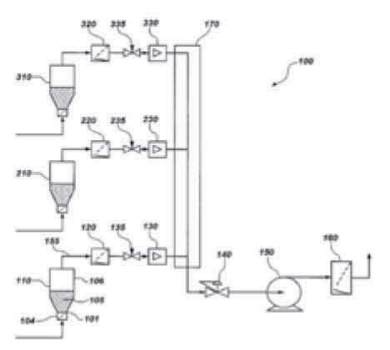



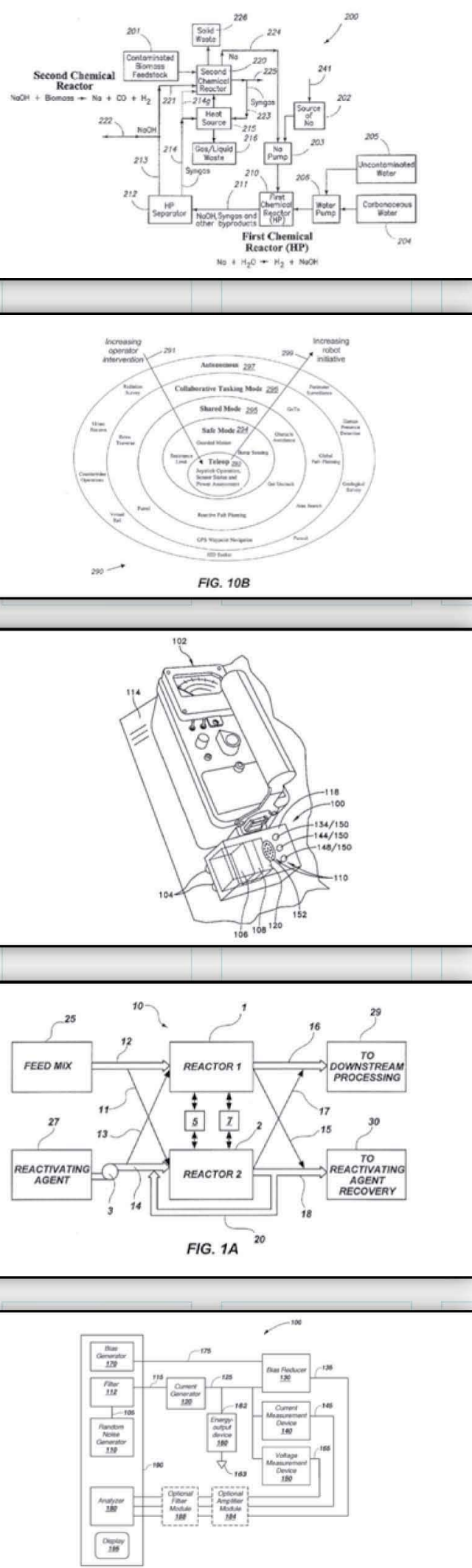

FIG. 3

\section{Method of Producing Hydrogen and Rendering a Contaminated Biomass Inert}

Dennis Bingham, Kerry Klingler, and Bruce Wilding were issued a patent for an invention that uses alkaline substances to render contaminated biomass useful and inert, while at the same time producing value-added hydrogen gas.

Patent Number: 7,665,328

Date Issued: Feb. 23, 2010

\section{Robotic Guarded Motion System and Method}

David Bruemmer was issued a patent for a control algorithm that ensures robots will come to a stop at a precise, specified distance from any obstacle regardless of the robot's initial speed, its physical characteristics, and the responsiveness of the low-level motor control. The guarded motion behavior permits the robot to take initiative to avoid collisions in response to laser and sonar range sensing of nearby obstacles. This improves the user's ability to traverse cluttered areas and limits the potential for users to be frustrated by robot initiative

Patent Number: 7, 668, 621

Date Issued: Feb. 23, 2010

\section{Hand-Held- Survey Probe}

Kevin Young and Kevin Hungate were issued a patent, which is an inexpensive, hand-held, battery operated device used to train people on maintaining the proper distance-from-surface and rate-of-movement, while surveying for radiation. The device can attach directly to an alpha or beta/gamma probe and provide continuous feedback to the user, improving safety for both radiation workers and emergency responders.

Patent Number: 7,667,854

Date Issued: Feb. 23, 2010

\section{System for Reactivating Catalysts}

Dan Ginosar, David Thompson and Raymond Anderson were issued a patent for an invention that allows the reuse of expensive alkylation catalysts, which are used in the petroleum industry to produce medium or large mass hydrocarbons from smaller molecules.

Patent number $7,670,568$

Date Issued: March 2, 2010

\section{Method and Apparatus for In-Situ Characterization of Energy Storage and Energy Conversion Devices}

Chet Motloch, John Morrison, Jon Christophersen and Wes Albrecht were issued a patent for this invention which allows the real-time, nonintrusive health evaluation of rechargeable batteries used in hybrid and electric vehicles. Battery charge and life expectancy can be constantly monitored with this system.

Patent Number: 7,675,293

Date Issued: March 9, 2010 


\section{Radio Frequency Detection Assembly and Method for Detecting Radio Frequencies}

Steve McCown and Kurt Derr were issued a patent on a system that allows the monitoring of a very large geographical area using passive radio frequency detection of cell phone signals. Security can instantly pinpoint the location of intruders and enable calls to the intruder's cell phone.

Patent Number: 7,680,502

Date Issued: March 16, 2010

\section{Internal Pressure Sensor}

James Dowalo was issued a patent for an invention that provides a reliable non-destructive method to accurately verify the integrity of spent nuclear fuel vessel seals. All other methods are inexact or require tapping into the canister to sample the internal atmosphere.

Patent Number: 7,677,106

Date Issued: March 16, 2010
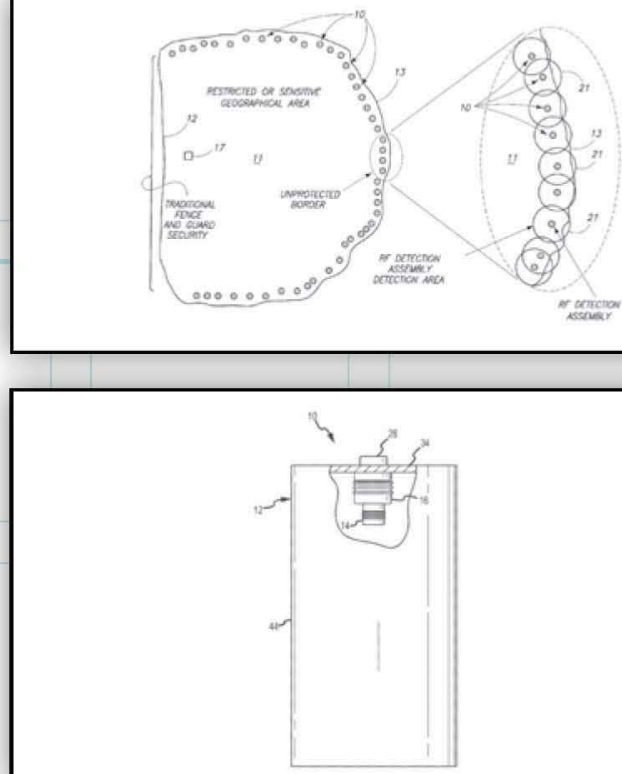

\section{Rapid Classification of Biological Components}

Two patents were granted to Vicki Thompson, Karen Barrett, and Diane Key for an invention that teaches non-skilled technicians how to analyze biological samples using antibody profiling technology, which positively identifies a person more accurately than fingerprints and DNA analysis and can be employed by non-skilled technicians.

Patent Numbers: 7,682,797 and 7,682,798

Date Issued: March 23, 2010

स.8

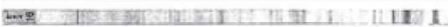

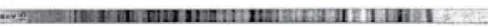

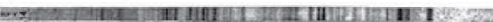

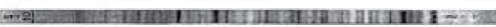

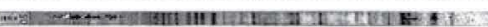

FIG. 1

\section{System and Method for Storing Energy}

A patent was granted to Dale Christiansen, David Spencer, Eric Yarger, John Richardson, and John Morrison for a self-recharging battery that employs a compressed magnetic field and a coil configured to focus this field into electrically conductive elements of the coil. The energy to recharge this battery may come from a walking motion or almost any other cyclic motion.

Patent Number: 7,688,036

Date Issued: March 30, 2010

\section{Method for Removing Impurities from an}

\section{Impurity-Containing Fluid Stream}

Dan Ginosar and Bob Fox were granted a patent for an invention that uses a unique solvent-based system to remove water from fat, oil, and fatty ester streams being used to produce biodiesel. This results in less catalyst being consumed and the minimization of soap production in the reaction process.

Patent Number 7,691,270

Date Issued: April 6, 2010
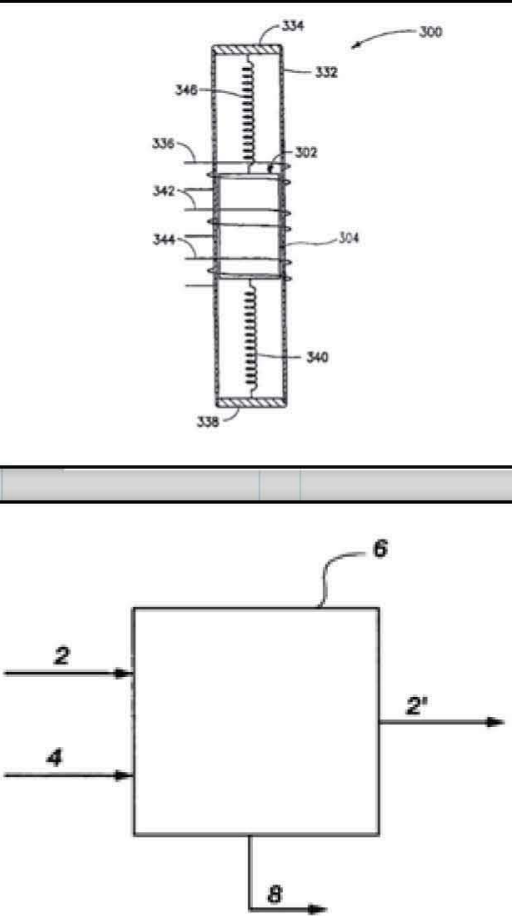

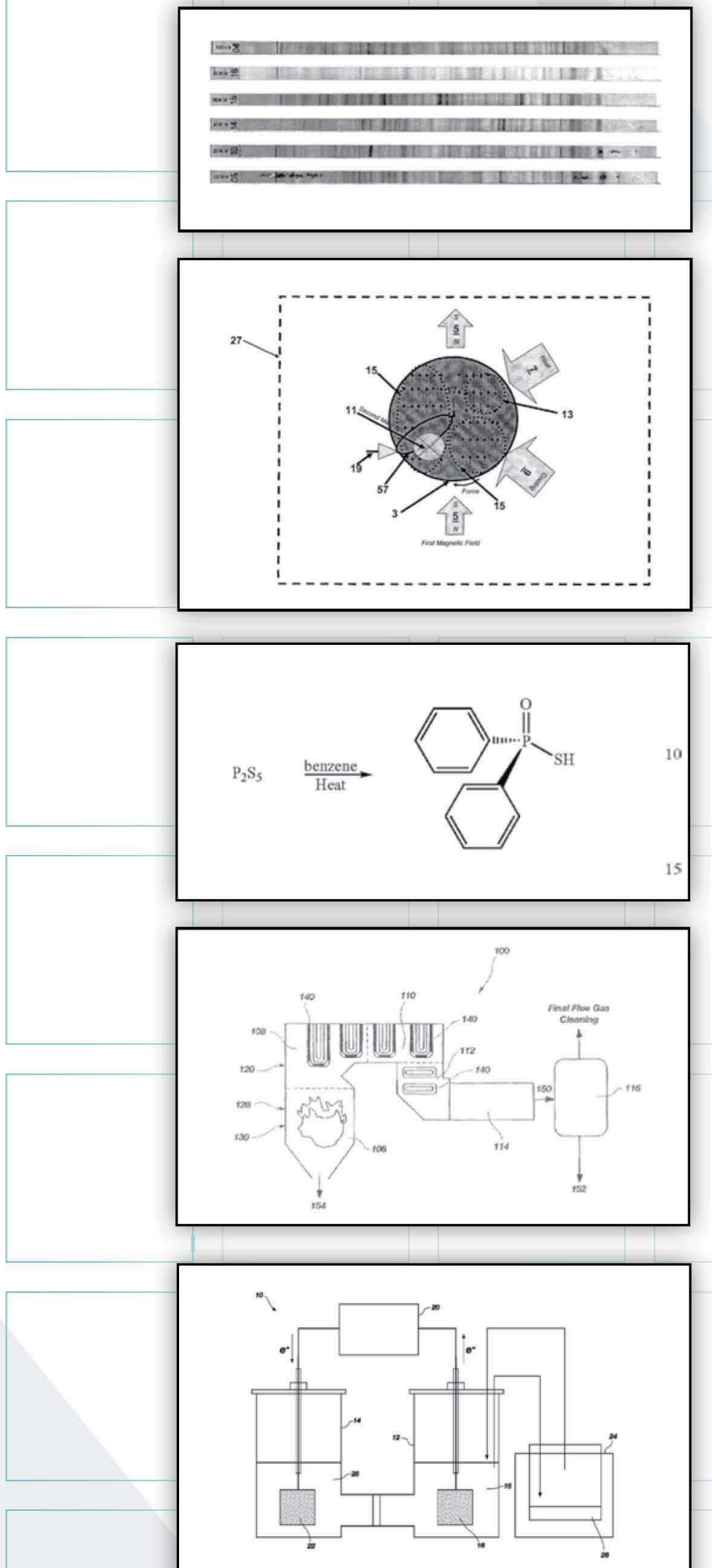

Improved Antibody Profiling Sensitivity through Increased Reporter Antibody Layering

Bill Apel and Vicki Thompson were granted a patent for a method to identify people and certain species of animals using certain specific antibodies contained in body fluids. This invention lowers the background reactions and increases by ten times the sensitivity of the antibody profiling technique.

Patent Number 7,695,919

Date Issued: April 13, 2010

\section{Thermal to Electric Energy Conversion Using Thermal Magnetic Properties}

Phil West and John Svoboda were issued a patent for their invention that converts heat into electricity via magnetocaloric variations in permeability. It could be used to power everything from personal computers to satellites. Patent Number 7,705,513

Date Issued: April 27, 2010

\section{Extraction Agent and Method for Forming an Extraction Agent for the Separation of Actinides from Lanthanides}

John Klaen, Mason Harrup, Jack Law, and Dean Peterman were issued a patent for an enhanced method for separating actinides from lanthanides. This invention enables the development of advanced nuclear fuel reprocessing that will allow complete actinide recycling and minimization of nuclear waste.

Patent Number: 7,704,468

Date Issued: April 27, 2010

\section{Oil Shale Derived Pollutant Control Materials and Methods and Apparatuses for Producing and Utilizing the Same}

Richard Boardman and Robert Carrington collaborated to invent a process to reduce pollution while producing oil from oil shale by producing pyrolysis gases and shale sorbents. The technology produces a high-activity multi-pollutant sorbent that will simplify emission control processes and reduce quantities of sorbent required. The invention supplants natural gas or heating fuel oil in some applications.

Patent Number 7,708,964 Date Issued: May 4, 2010

\section{Methods for Performing Electrochemical Nitration Reactions}

Ted Lister and Robert Fox were issued a patent for the electrochemical synthesis of dinitro compounds by oxidative nitration of a nitro compound. This process dramatically reduces the amount of waste produced while synthesizing these compounds. Dinitro compounds are precursors for the plasticizers used to manufacture explosives and propellants.

Patent Number 7,713,401

Date Issued: May 11,2010 


\section{Conversion of Crop Seed Oils to Jet Fuel} and Associated Methods

Daniel Ginosar, Lucia Petkovic, and David Thompson were granted a patent that teaches the production of jet fuel from biological sources through hydro-cracking and reforming to replace petroleum-based fuels. The process produces its own heat and hydrogen thus increasing the cost and effectiveness of the product and reducing the capital equipment costs.

Patent Number 7,718,051

Date Issued: May 18, 2010
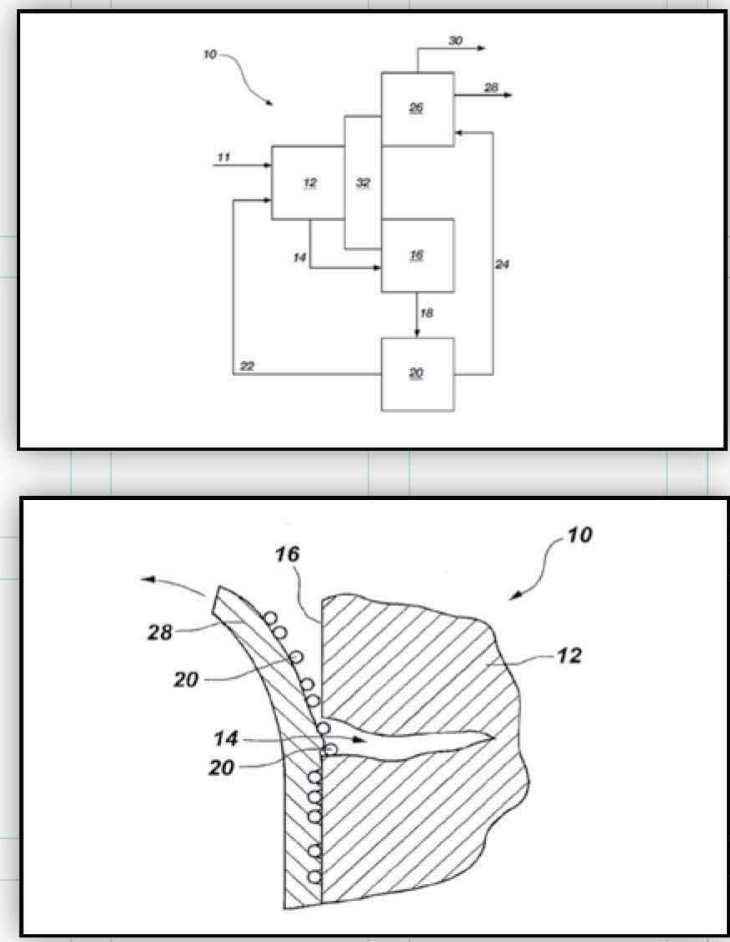

\section{Decontamination Materials, Methods for Removing} Contaminant Matter from a Porous Material, and Systems and Strippable Coatings for Decontaminating Structures that include Porous Material

Robert Fox, Recep Avci, and Gary Groenewold collaborated on a method of removing contaminated material from porous surfaces by applying a polymer material and irradiating the contaminated surface with a laser to cause the contamination to move from the surface to the polymer. This process proved successful at removing cesium from cement, granite, marble, and clay materials resulting from a contaminating incident.

Patent Number: 7,723,463

Date Issued: May 25, 2010

\section{Enzyme and Methodology for the Treatment of a Biomass}

Vicki Thompson, David Thompson, Kastli Schaller, and William Apel were issued a patent for a biomass treatment. This invention describes an enzyme produced by Alicyclobacillun acidocaldarius (an extremophile found in hot springs in Yellowstone National Park), which works in very acidic and high temperature environments to facilitate the treatment of biomass.

Patent Number: 7,727,755

Date Issued: June 1, 2010

\section{Radiation Analysis Devices, Radiation Analysis Methods, and Articles of Manufacture}

Lyle Roybal is the sole inventor of a software system that automatically adjusts the region of interest examined by a radiation detector to compensate for gain changes that effect energy calibration in the detector. This method greatly improves the accuracy and data quality of the detector.

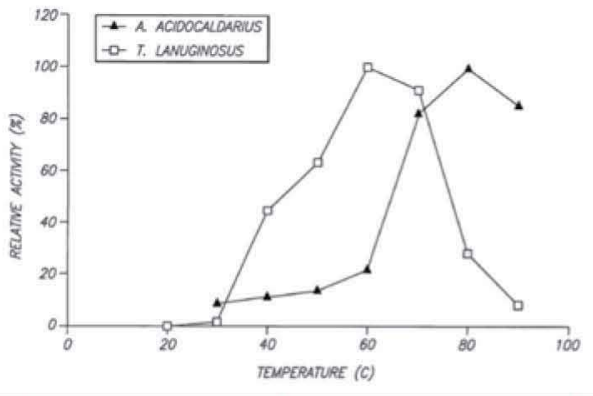

Patent Number: 7,732,785

Date Issued: June 8, 2010

\section{Actinium Radioisotope Products of Enhanced Purity}

A patent was issued to David Meikrantz, Terry Todd, Troy Tranter, and Philip Horwitz for using the centrifugal contactor to continuously remove isotopes that are useful for treating cancer from breeder reactor fuel. This technology was adapted for cleaning water contaminated with oil and is being used to ameliorate the environmental disaster in the Gulf of Mexico.

Patent Number: 7,736,610

Date Issued: June 15, 2010
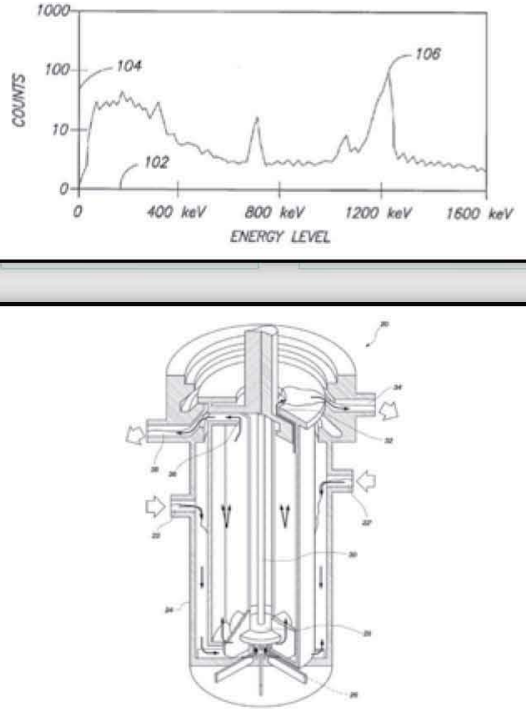


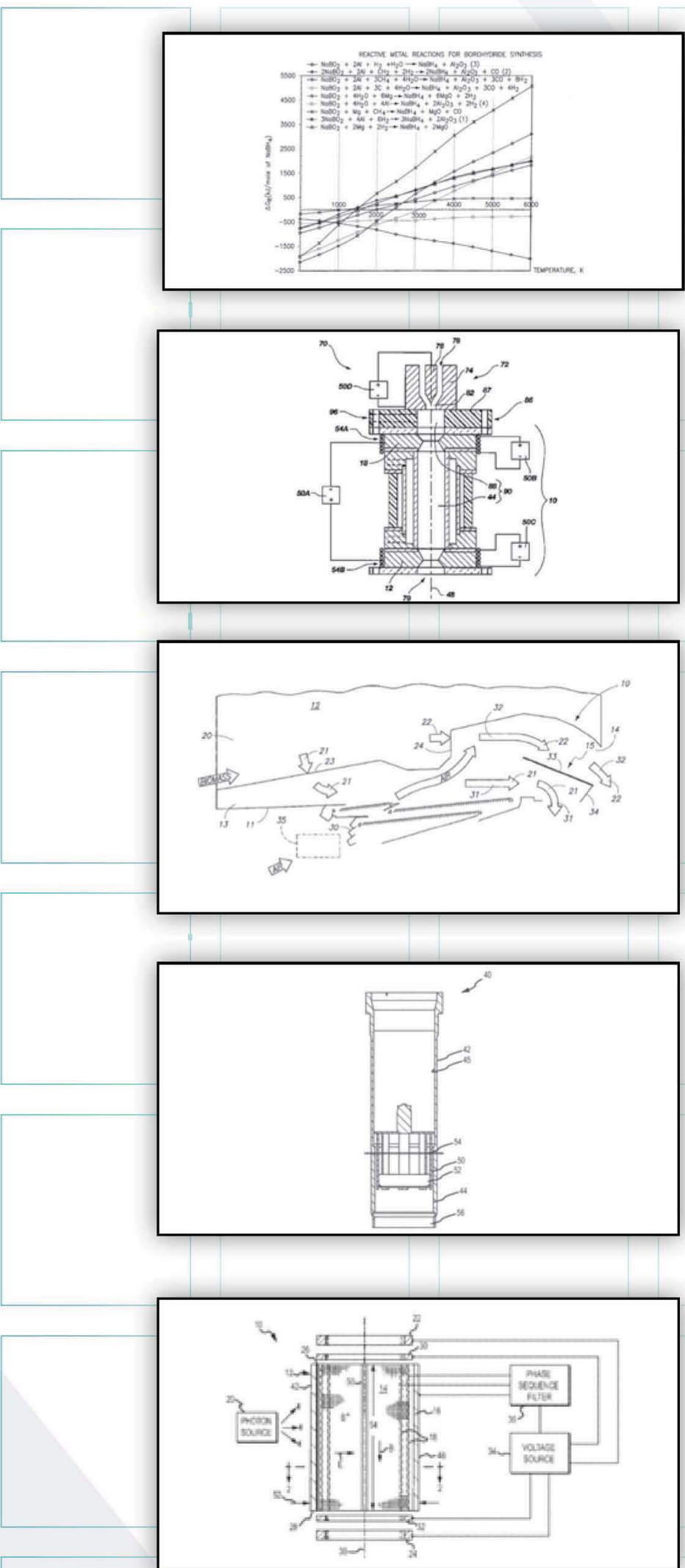

\section{Method for Producing a Borohydride}

Peter Kong received a patent for producing borohydride from borate and reducing material in a single step reactive metal combustion process. Borohydride is used to store hydrogen for fuel cells and this cost-effective production of borohydrides takes the use of fuel cells for transportation one step closer to reality.

Patent Number: 7,741,428

Date Issued: June 22, 2010

\section{Modular Hybrid Plasma Reactor and Related Systems and Methods}

Brent Detering, Jon Grandy and Peter Kong received a patent for an invention that generates plasma by a direct current electric arc which is selectively controlled to establish a circular or helical path within the plasma chamber. This reactor can produce nano-particles from large solid feed materials and was invented under a CRADA with PPG Industries.

Patent Number: 7,741,577

Date Issued: June 22, 2010

\section{Particulate Residue Separator and a Method for Separating a Particulate Residue Stream}

Christopher Wright, J R Hess, Kevin Kenney and Reed Hoskins were issued a patent on this biomass separator system that preprocesses feedstock in the field during harvest. It reduces the cost and increases the quality of feedstocks delivered to biorefineries.

Patent Number: $7,744,450$

Date Issued: June 29, 2010

\section{High Current Density Cathode for} Electro-refining in Molten Electrolyte

Shelly $\mathrm{Li}$ received a patent for a new electro-refiner that improves the recovery of uranium and plutonium from spent nuclear fuel in a molten salt electrolyte. Her invention is an insulated stainless steel tube with multiple perforations which exposes the tube interior surface and creates a high current density cathode that is capable for a current density of three amps per square centimeter. This electro-refiner is capable of greater efficiencies and throughputs than conventional electro-refiners. $\mathrm{Dr}$. $\mathrm{Li}$ is currently serving a two year term with the International Atomic Energy Agency (IAEA) in Vienna, Austria.

Patent Number: 7,744,734

Date Issued: June 29, 2010

\section{Methods and Apparatus for Producing and Storing Positrons and Protons}

Doug Akers was issued a patent for an invention which uses electric and magnetic fields to store protons or positrons (anti-matter). Positron storage is being considered for power applications, including rockets, because of the high power density associated with positrons. Current methods use a sodium-22 source, which produces positrons and are difficult to encapsulate in electromagnetic storage. This system uses a photon source (an accelerator) and a source material that emits positrons to effectively trap and store positrons until needed.

Patent Number: 7,750,325

Date Issued: July 6, 2010 


\section{Polybenzimidazole Compounds}

Inventors John Klaehn, Eric Peterson, Alan Wertsching, Christopher Orme, Thomas Luther and Michael Jones were granted a patent for a straightforward synthesis that can be carried out at room temperature and produces a polybenzimidazole (PBI) that is orders of magnitude better than the parent compound and much more soluble in organic solvents. PBI (also known as Celazole) is resistant to strong acids, bases, and high temperatures. Celazole is the world's leading flame-resistant fiber and is used for fire fighters' clothing, space suits, and for high performance engineering thermoplastic.

Patent Number: 7,772,361

Date Issued: Aug. 10, 2010

\section{Microwave Assisted O il-Water Analytical Centrifuge}

David Meikrantz was issued a patent for incorporating a microwave energy emitter into the centrifugal contactor previously patented by $D r$. Meikrantz. This microwave enhancement improves the efficiency of the device to over 99.9 percent efficiency in separating oil from water.

Patent Number: 7,775,961

Date Issued: Aug. 17, 2010

\section{Method and Apparatus for lon Cyclotron Specrometry}

David Dahl, Jill Scott, and Tim McJunkin cooperated on a patented invention that causes an ion traversing the spectrometer to experience no change in cyclotron frequency. The patented cell allows all ions, regardless of mass, to be excited to the same radius throughout the cell. Since all of the ions are at the same radius, the measured abundances accurately reflect the number of each type of ion in the cell. Although this was designed specifically for isotope ratio measurements, it has some additional desirable attributes. The ion clouds are more coherent and in-phase than in traditional cells, which also improves resolution and mass accuracy as well as the accuracy of the abundance of ions. In addition, this cell design allows for wider mass-to-charge ranges to be observed with the same trapping and excitation parameters.

Patent Number: 7,777,182

Date Issued: Aug. 17, 2010

\section{Methods, Apparatus, and Systems for}

\section{Monitoring Transmission Systems}

Clark Scott, Gail Heath, John Svoboda, Phil West, and Robert Polk received a patent for an invention which provides real-time status of the integrity of the physical structure of power poles and transmission towers. It may also be applied to other structures, such as pipelines and cell towers, which have multiple segments that can cover hundreds of miles. Sensors and on-board processing provide indication of tampering or impending damage to the power line structures. Information is provided by the system to the central operations center or supervisory control and data acquisition (SCADA) for corrective actions. The system can also be used to detect vehicular or low flying aircraft traffic in the near vicinity of the transmission tower and provide an alert to a system communications end point.

Patent Number: 7,786,894
Date Issued: Aug. 31, 2010
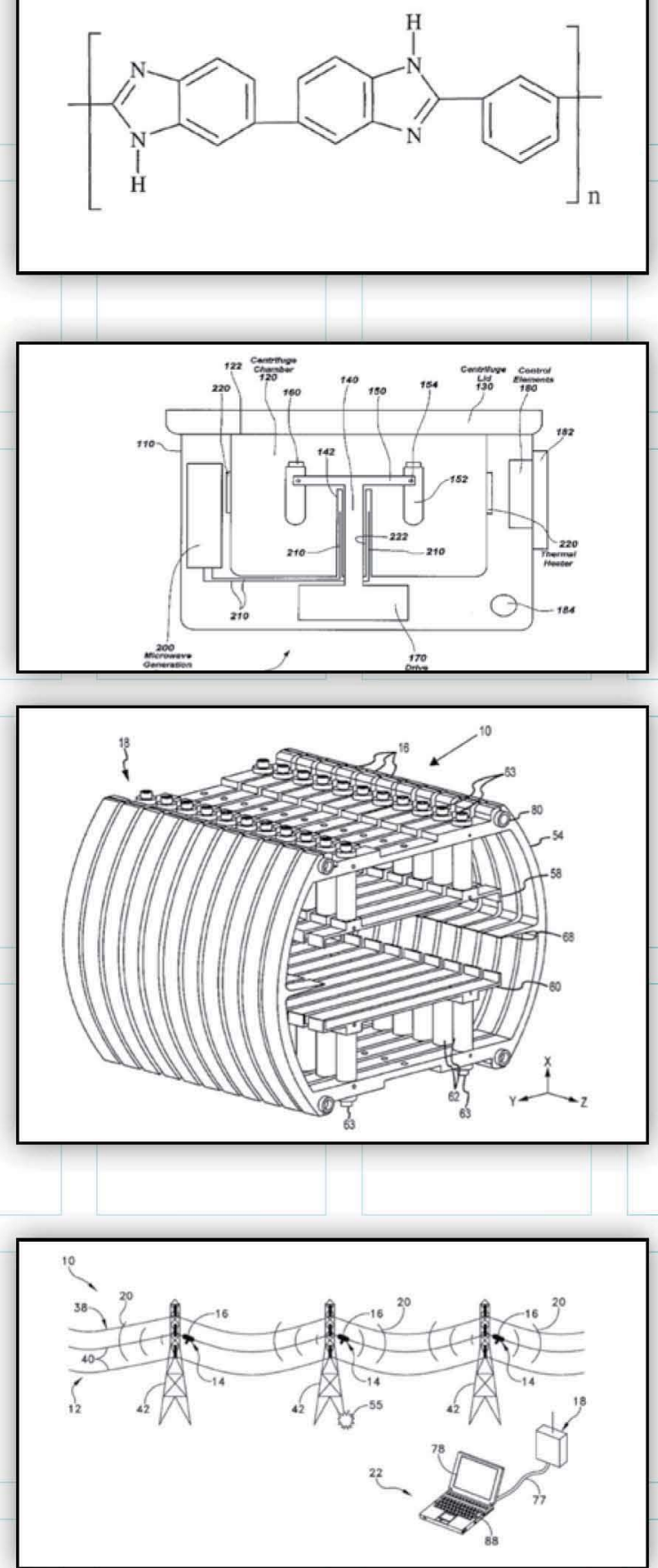

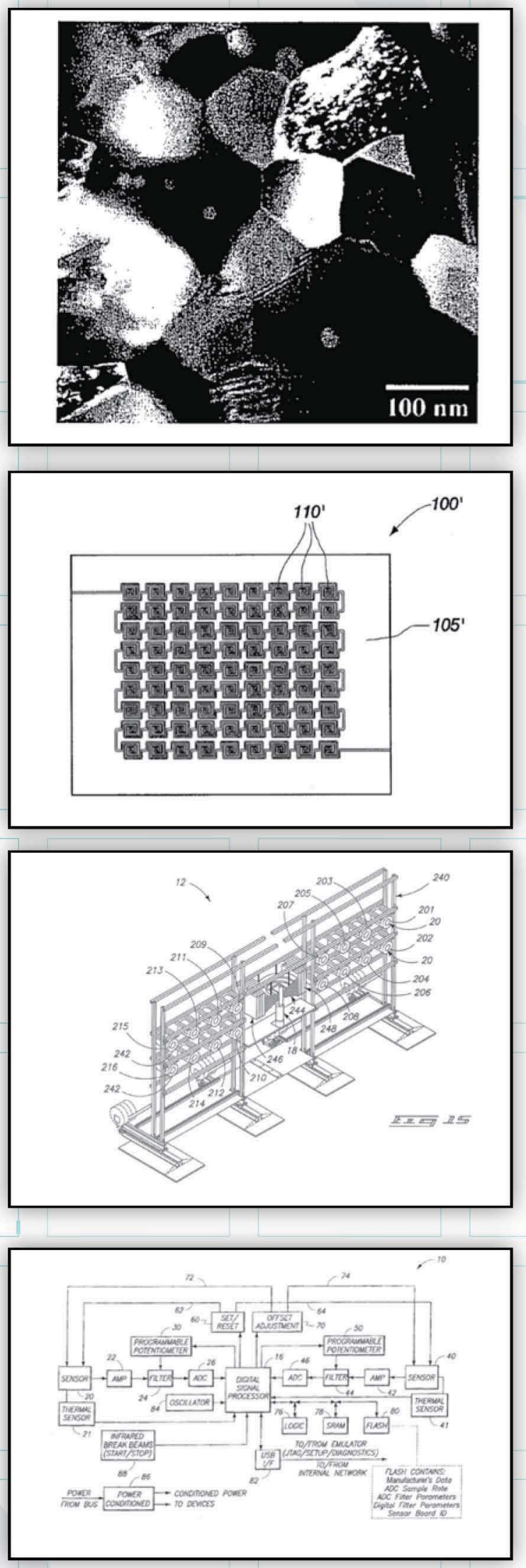

\section{A Method of Forming a Hardened Surface on a Substrate}

Daniel Branagan, now of the Nanosteel Company (an INL spinout), was granted a patent for an invention that advances the art of rolling a metal strip and powdered metal to form a wire. The wire is then applied to a metallic surface to form a layer of metallic glass and convert the glass to a nano-crystalline material. This material has a melting temperature between $1,1000 \mathrm{C}$ and $1,2500 \mathrm{C}$ and a hardness of about $9.2 \mathrm{GPa}$. The hardest stainless steel has a hardness of about 1.3 GPa.

Patent Number: 7,785,428

Date Issued: Aug. 31, 2010

Methods, Computer Readable Media, and Graphical User Interfaces for Analysis of Frequency Selective Surfaces

A patent for "Methods, Computer Readable Media, and Graphical User Interfaces for Analysis of Frequency Selective Surfaces" was granted to Kale Kotter and David Rohrbaugh. Frequency selective surfaces are used in a wide variety of applications including radomes, dichoric surfaces and circuit analog absorbers. This invention is an improved method of modeling, analyzing, and designing frequency selective surfaces in the infrared and visible light spectrum and up to TeraHetrz frequencies.
Patent Number: 7,792,644
Date Issued: Sep. 7, 2010

Method and System for Calibrating Acquired Spectra for Use in Spectral Analysis

Edward Reber, Kenneth Rohde, and Larry Blackwood were granted a patent for a spectral analysis method that employs neutrons and multiple sodium iodide detectors to quickly and accurately inspect cars and trucks for explosives detection.

Patent Number: 7,795,595

Date Issued: Sep. 14, 2010

\section{Circuitry, Systems, and Methods for Detecting Magnetic Fields}

Dale Kotter, David Spencer, David Rohrbaugh, and Lyle Roybal received a patent for an improved weapons detector portal with a low falsepositive rate that can quickly determine the difference between threatening and non-threatening objects concealed in clothing. This system was developed under a CRADA with the Walt Disney Company.

Patent Number: 7,796,028

Date Issued: Sep. 14, 2010 


\section{Generic Robot Architecture}

David Bruemmer and Doug Few were granted a patent for "Generic Robot Architecture or Robot Intelligence Kernel" (RIK) a generic scalable robot architecture that provides a framework that is easily portable to a variety of robotic platforms. This RIK architecture provides hardware abstractions, generic robot attributes and robot behaviors.

Patent Number: 7,801,644

Date Issued: Sep. 21, 2010

\section{Actinide Extraction Methods and Actinide Separation Compositions}

A patent was granted to Dean Peterman, Jack Law, John Klachn, Mason Harrup, and Richard Tillotson for an invention that reduces the secondary waste and simplifies the process of separating actinides from lanthanides in nuclear fuel. This invention can also be used to separate actinides from one another.

Patent Number: 7,799,293

Date Issued: Sep. 21, 2010

\section{Electromagnetic Wrap}

A patent for "Electromagnetic Wrap" was granted to Jill Scott and Paul Tremblay for a method of altering the effects of reactive components of a power transmission line without altering its physical characteristics or reducing the strength of the transmitted signal. This invention is essential for the efficient operation of Fourier Transform Ion Cyclotron Resonance Mass Spectrometers (FTMS) and useful for supporting the stepper motors that control welding in high radiation fields.

Patent Number: 7,804,029

Date Issued: Sep. 28, 2010
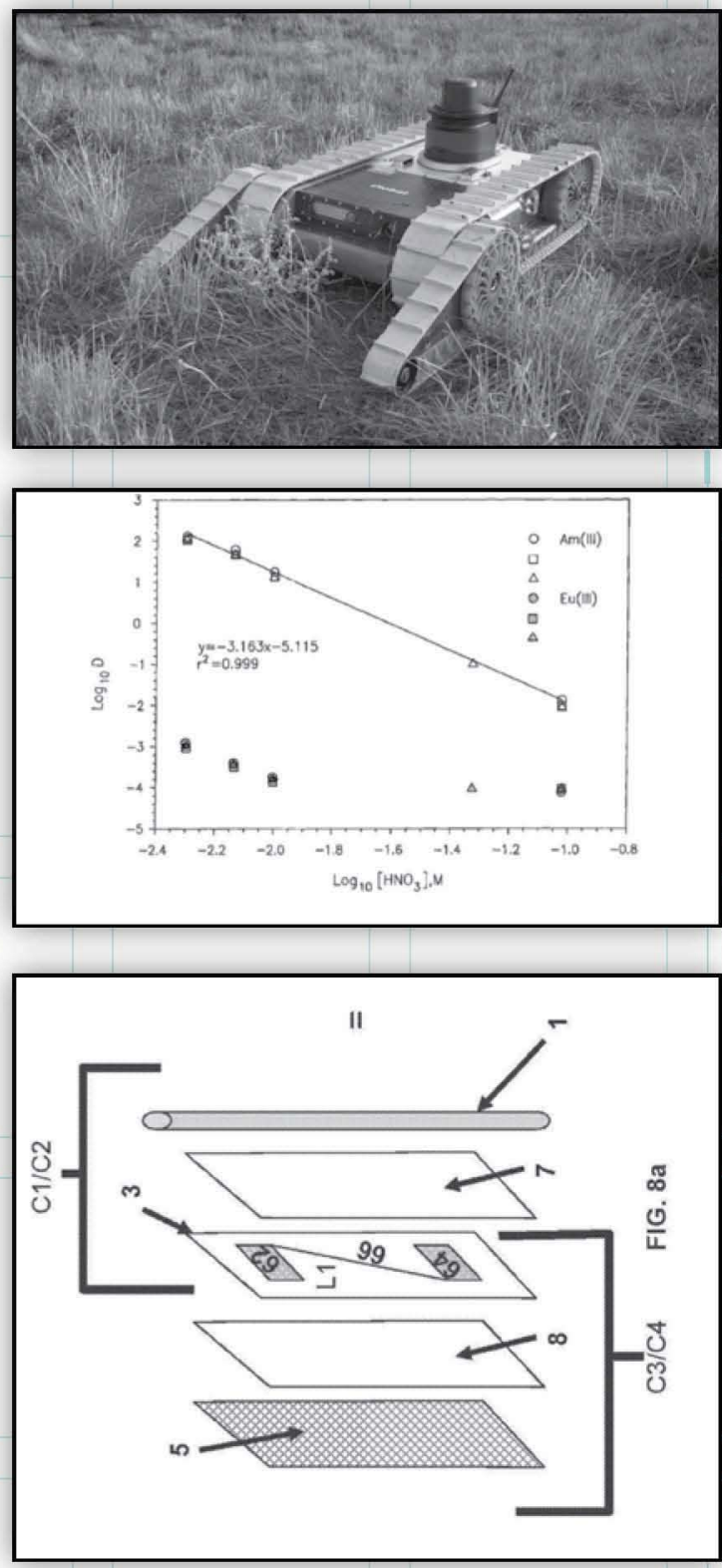


\section{Granted Copyrights}

INL received permission to assert copyright for five newly developed software applications.

\begin{tabular}{|l|l|}
\hline Copyrighted Software & Authors \\
\hline Multi-Reactor Design and Analysis Platform & $\begin{array}{l}\text { Joshua J Cogliati, Michael L Milvich, } \\
\text { Rodolfo Mike Ferrer, Charles A Wemple, } \\
\text { Daniel E Wessol }\end{array}$ \\
\hline Geomechanical Fracturing with Flow and Heat & $\begin{array}{l}\text { Thomas R Wood, } \\
\text { Hai Huang, Zhije Xu }\end{array}$ \\
\hline Needle Federated Search Engine & $\begin{array}{l}\text { Barry K Hansen, David N Handy, } \\
\text { Emert Follett, Jackie Loop, Jennifer Hope Forsmann, } \\
\end{array}$ \\
& $\begin{array}{l}\text { Lee R Kerns, Sam Allred, Sandra L Biermann, } \\
\text { Scott Jeffery, Wayne W Simpson }\end{array}$ \\
\hline OgINet & Jared A Verba \\
\hline Multiphysics Objects Oriented Simulation Environment & Derek Gaston, \\
& Cody Permann, Glen Hansen \\
\hline
\end{tabular}

Multi-Reactor Design and Analysis Platform. MDRAP software simplifies the creation, transfer and processing of data between computational codes. It allows each integrated code, through a plug-in interface, to specify the required input for execution and the required output needed. It also creates an interface for execution and data transfer. A Graphical User Interface (GUI) assists with input preparation and data visualization.

Geomechanical Fracturing with Flow and Heat. This software is used to simulate rock fracturing with heating and the change in fluid flow properties of the rock after fracturing.

Needle Federated Search Engine. The software is used to research across a wide variety of information repositories with a flexible search interface that allows end users to point at any available data source.
OglNet. The software is used to capture and visualize network packets as they move from their source to their intended destination. This creates a three-dimensional representation of an active network and can show misconfigured components, potential security breaches and possible hostile network traffic.

Multiphysics Objects Oriented Simulation Environment. The MOOSE software is used as an interface for scientists to develop analysis applications by accepting weak forms of the mathematical models that govern the behavior of the physical system being modeled. It combines computer science with a strong underlying mathematical description in a unique way that allows scientists and engineers to develop engineering simulation tools in a fraction of the time previously thought necessary. 


\section{Royalties}

Royalties have reached more than $\$ 6.5$ million during the past six years at INL, varying each year from about $\$ 800,000$ in FY2005 to more than $\$ 1.6$ million in FY2009. During FY2010, INL earned \$1,038,344 in royalties, which reflects an expanding portfolio of intellectual property and increased attention to commercialization of these discoveries and inventions.

Legislation governing INL technology transfer activities authorizes the laboratory to retain and use funds generated through the licensing of technology. This licensing income can be used in a variety of ways, including monetary rewards to encourage inventors in their research and further investment in developing and transferring technologies from the Laboratory into the marketplace. In FY2010, INL institutionalized a new laboratory wide procedure (LWP-22231) for managing royalties that provides for transparency and strategic utilization of royalties.

The generation of these significant monetary returns demonstrates that INL-developed technologies are competitive in commercial markets. The licensing of nearly 500 technologies from FY2005 to FY2010 and the significant economic impact these transactions have made underscores that INL is succeeding in its mission to transfer technologies to the public.

INL has strategically invested the income retained from licensing activities to fund additional mission-related research and development, reward other laboratory employees who contribute significantly to the transfer and utilization of INL technology, employ education and training related to the $R \& D$ mission, and other activities that increase the licensing potential of laboratory technology, such as INL's Innovation Development Fund (IDF).

In its short history, INL's IDF has been very successful in its objective to enhance the likelihood of transferring laboratory developed technologies to nonfederal parties to meet the purposes of technology transfer legislation. IDF projects have also brought INL technology closer to the market so that the U.S. public can benefit from INL research. A large part of the fund's success may be attributed to the fund's focus on commercial outcome.

The following INL Innovation Development Fund projects were funded in FY2010:

Carbide Fiber

John Garnier

Aluminum Oxynitride Material and Bodies Michael Bakas

Metal Matrix Composite Armor. Kevin McHugh

Imaging Manipulation David Crandall

Plasma Engine Peter Kong

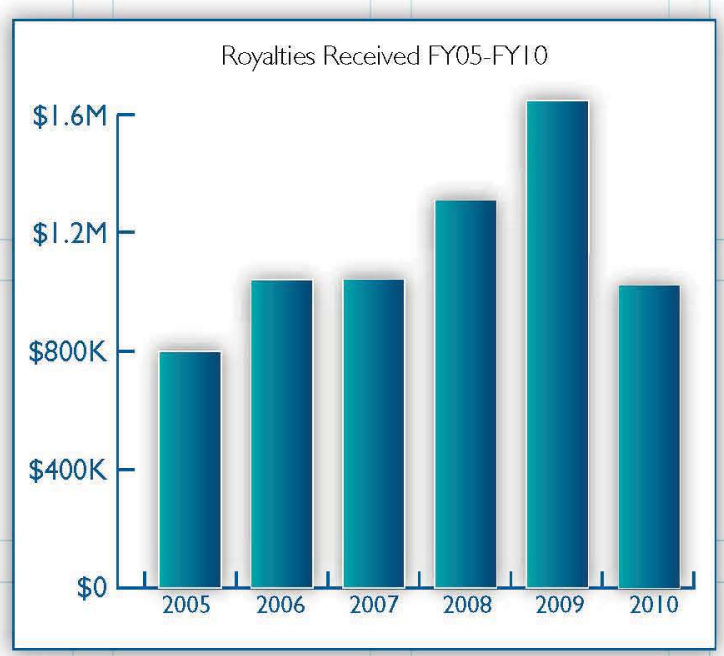

\section{License Agreements}

License agreements between INL and a business (or other entity) allow the business to reproduce, manufacture, sell, or use INL-developed or owned intellectual property. INL contractor-owned inventions are available for licensing and commercialization by U.S. and foreign companies and organizations. INL licenses its intellectual property on much the same terms as universities, and other research organizations and industrial firms.

During the past six years, INL has signed nearly 500 licenses that have earned more than $\$ 6.5$ million in royalty fees. For FY2010, INL signed ten new patent licenses and two option licenses. A summary of those negotiations is provided below. In addition, INL executed 27 copyright licenses (13 fee licenses, 14 no-fee licenses), which brought total licensing agreements to 39 during FY2010.

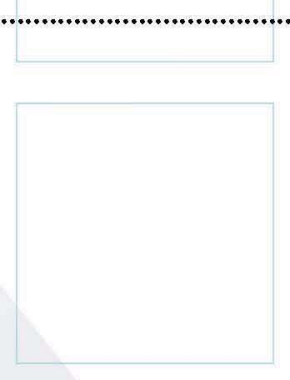

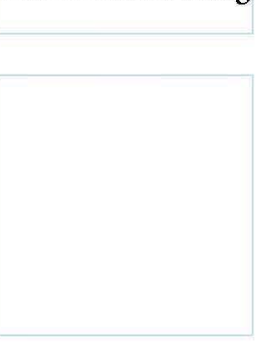

h

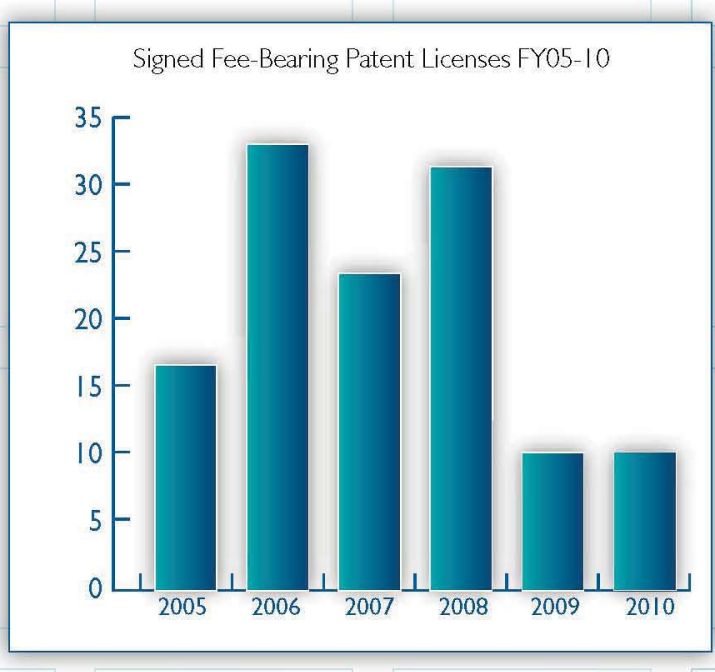




\section{Summary of INL Patent Licenses FY20I0}

\begin{tabular}{|c|c|}
\hline Licensee & Technology \\
\hline Apollo Optical Systems & $\begin{array}{l}\text { Patent license, Sighting Optics and Methods for Sighting: } \\
\text { Nov. } 2009\end{array}$ \\
\hline Western Hydrogen Ltd & $\begin{array}{l}\text { License option modification, Production or Process for } \\
\text { Hydrogen to be Distributed. Dec. } 2009\end{array}$ \\
\hline Premier Technology & $\begin{array}{l}\text { License modification, Coated Armor System \& Process for } \\
\text { Making the Same, signed December } 2009\end{array}$ \\
\hline Applied Research Associates, Inc. & $\begin{array}{l}\text { Patent and copyright license, Robotic Intelligence Kernel, } \\
\text { March } 2010\end{array}$ \\
\hline Identity Sciences, LLC & $\begin{array}{l}\text { License option, Identification of Discriminant Proteins through } \\
\text { Antibody Profiling, Methods, and Apparatus for Identifying an } \\
\text { Individual, March } 2010\end{array}$ \\
\hline Xebec Adsorption, Inc. & $\begin{array}{l}\text { License modification, Vectored Natural Gas from a Pipeline, } \\
\text { April } 2010\end{array}$ \\
\hline Identity Sciences, LLC & $\begin{array}{l}\text { License modification, Antibody Profile Analysis System and } \\
\text { Method, May } 2010\end{array}$ \\
\hline 5D Robotics, Inc. & $\begin{array}{l}\text { Patent and copyright license, Robotic Intelligence Kernel, } \\
\text { Aug. } 2010\end{array}$ \\
\hline Princess Energy Systems, Inc. & License modification, Safe Battery Solvents, Aug. 2010 \\
\hline The NanoSteel Company, Inc. & $\begin{array}{l}\text { License modification, Methods of Forming Steel and Hard } \\
\text { Metallic Materials, Hard Metallic Coatings, Methods of } \\
\text { Processing Metallic Materials and Methods of Producing } \\
\text { Metallic Coatings, Aug. } 2010\end{array}$ \\
\hline $\begin{array}{l}\text { North Wind, Inc. } \\
\text { (2 agreements) }\end{array}$ & $\begin{array}{l}\text { Patent license, Method, Apparatus, and System for Low-Energy } \\
\text { BETA Particle Detection and Multi-Detector Probe, Aug. } 2010\end{array}$ \\
\hline SRI International & $\begin{array}{l}\text { Copyright license, "Robotic Intelligence Kernel", Jan. } 2010 \\
\text { and renewed in June } 2010 \text { - non-fee bearing }\end{array}$ \\
\hline
\end{tabular}

Technology Deployment successfully pursued several actions in support of INL's efforts to engage the nuclear industry. Specifically, licenses were negotiated for intellectual property specializing in characterizing nuclear materials when present and nearly two dozen for the RELAP5-3D thermo-hydrodynamic modeling tool.

\section{North Wind:Two Licenses to Advance Subsurface Science Soil Analysis Studies}

INL continues to expand its leadership among the nuclear industry by negotiating two licensing agreements pertaining to environmental research. In August, North Wind, Inc., a CIRI company, signed an agreement for exclusive rights to practice patent application for "Apparatuses and Methods for Radiation Detection and Characterization Using a Multiple Detector Probe," Oct. 2009. The company, also signed an agreement for exclusive rights to practice patent application for "Method, Apparatus and System for Low-Energy Beta Particle Detection" in the field of subsurface soil analysis, Jan. 2010.

The INL Multi Detector Probe (MDP) characterizes a broad range of subsurface transuranic and spent fuel radioactive wastes and is being used at the Hanford site to assist in developing safe remediation plans for monitoring these wastes. MDP is capable of differentiating low activity transuranic materials from high activity materials by using this two-inch diameter probe and software system. 


\section{RELAP License Summary FY20 I0}

\begin{tabular}{|c|c|c|c|c|}
\hline & Commercial & University & Government & Total \\
\hline Domestic & $\begin{array}{l}\text { Arizona Public Service } \\
\text { L-3 Communications MAPPS } \\
\text { Inc. } \\
\text { Industrial Leak Detection, Inc. } \\
\text { General Dynamic Electric } \\
\text { Boat Division } \\
\text { CD Adapco } \\
\text { GSE Power Systems, Inc. }\end{array}$ & $\begin{array}{l}\text { University of Wisconsin - } \\
\text { Madison } \\
\text { University of Michigan } \\
\text { University of Tennessee, } \\
\text { Knoxville } \\
\text { Oregon State University } \\
\text { The University of Akron } \\
\text { University of California, } \\
\text { Berkeley } \\
\text { Georgia Technology Research } \\
\text { Corporation }\end{array}$ & $\begin{array}{l}\text { Lawrence Livermore National } \\
\text { Security (LLNS), LLC } \\
\text { Los Alamos National Security, } \\
\text { LLC }\end{array}$ & \\
\hline Sub total & 6 & 7 & 2 & 15 \\
\hline International & $\begin{array}{l}\text { Mitsubishi Nuclear Energy } \\
\text { Systems, Inc., Japan } \\
\text { Areva NP Inc., France/US } \\
\text { Rolls Royce Power } \\
\text { Engineering Ltd, England } \\
\text { Tecnatom SA, Spain }\end{array}$ & $\begin{array}{l}\text { Kalsruhe Institute of } \\
\text { Technology, Germany } \\
\text { Universidade Federal de } \\
\text { Minas Gerais, Brazil }\end{array}$ & $\begin{array}{l}\text { Institute of Nuclear Safety } \\
\text { Systems, Inc. Japan } \\
\text { Japan Nuclear Energy Safety } \\
\text { Organization, Japan } \\
\text { Nuclear Research Institute Rez, } \\
\text { PLC, Czech Republic }\end{array}$ & \\
\hline Sub total & 4 & 2 & 3 & 9 \\
\hline Total & 10 & 9 & 5 & 24 \\
\hline
\end{tabular}

\section{INL Grows RELAP Licensing Program in Support of Nuclear} Energy Research and Operations during FY2010

Advancing nuclear research depends on having reliable and trusted modeling tools. For many years, RELAP5-3D has been widely used by the international nuclear community to support research and nuclear studies, including safety analysis and evaluating innovative ideas. INL has developed RELAP5-3D, the latest in the RELAP5 code series, for the analysis of transients and accidents in water-cooled nuclear power plants and related systems, as well as the analysis of advanced reactor designs. RELAP5-3D is known for its fully integrated, multi-dimensional thermal-hydraulic and kinetic modeling capability, and the analysis of advanced reactor designs. A related code called RELAP5-RT, a real-time version of RELAP5-3D, is licensed nonexclusively to several companies who integrate the code with their simulation software and make the resulting simulation tool available to end users.
Technology Deployment has successfully negotiated 19 licenses and three license modifications during FY2010. Renewed industrial interest and a focus on improving the RELAP5-3D licensing process has enhanced INL's mission of advancing nuclear safety and research.

In summary, updating and expanding RELAP5-3D agreements contributes to INL's goal to establish broader and more effective engagement within the nuclear industry and the research community. It benefits the public by enabling the advancement of nuclear energy with important modeling tool, which aids the revitalization of the world's nuclear power industry.

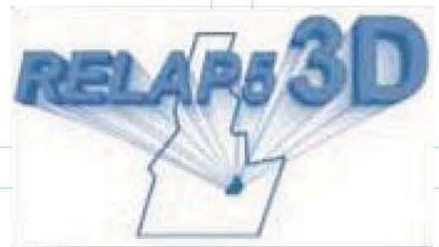




\section{INL Uses Innovative Approach to License Award-winning MicroSight Technology}

The MicroSight is an innovative gun sight technology developed at INL that seems to transcend the laws of physics by enabling shooters to focus on both the sight and target simultaneously (see Figure 1). The optical invention is elegant, economical, aesthetically pleasing and light weight.

MicroSight offers dramatic improvement of both firearm safety and performance delivering the capability of precise aiming and superior sight accuracy when shooting. A small investment in this light weight optical device will provide U.S. military members better vision and superior performance. This also is true for the nearly 35 million hunters and target shooters in the U.S. and millions more around the world. The MicroSight is useful particularly to sportsmen and target shooters experiencing declining eyesight by essentially turning back the clock for these gun enthusiasts. MicroSight permits them to continue enjoying the sport, while ensuring safer shooting.

Commercialization manager Lisa Nate and inventor David Crandall formed a strong, synergistic team in pursuing the transfer of MicroSight to the private sector. Safeguarding INL's intellectual property and properly executing licensing mechanisms were their primary interests and contributions.

Believing very strongly in this technology, Nate carefully monitored and advanced the patent process in readying the technology for transfer. She innovatively advanced the tech nology transfer processing by leveraging INL internal funds to produce prototypes to demonstrate the effectiveness of MicroSight. Working closely with Daniel McGarry, President of Apollo Optical Systems, they took another innovative step in having $A O S$ produce their own prototypes to validate manufacturing before licensing.

Crandall has earned many marksman trophies being the first Idahoan to win National Rifle Association (NRA) Long Range High Master certification, and serves as a current and past U.S. National Team Member. He has a thorough knowledge of the sport shooting industry and optics has long been a personal hobby interest. This insight offered a special advantage and contribution to the technology transfer effort for MicroSight. Crandall's personal interest in sport shooting and his support of INL's national security missions made for a happy marriage that produced a special contribution to technologies aiding U.S. defense and security forces.

Of course, initially the traditional technology transfer elements were used with Nate ensuring that patent information was accurate and complete. Then, she made numerous cold calls, delivered numerous demonstrations and attended trade shows to determine interest and identify a strong and research driven optical manufacturer.

Once the internal concept tests were complete, the duo of Nate and Crandall exhibited the technology at innovative trade shows. More than 3,000 hours were spent in demonstrations, development discussions, licensing preparation and technology application research. This expense of shoe leather and dedicated time produced a highly successful licensing agreement with AOS that will soon have this marvelous optic available for U.S. military and worldwide sport shooting enthusiasts in 2011.
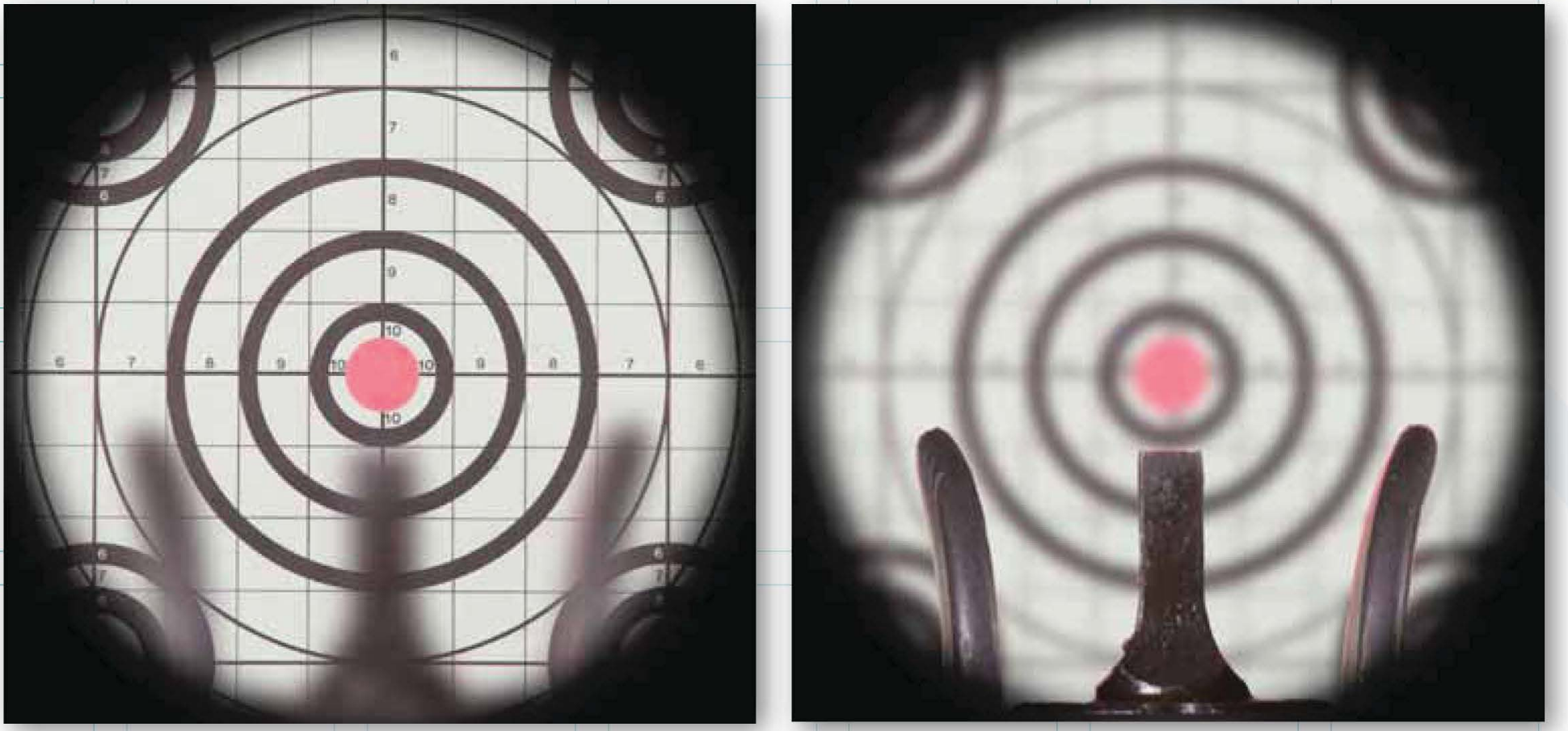

Figure I: Humans can focus on either the target (left) or the iron sight (center), but not both. MicroSight allows the eye to focus on both the target and the iron gun sight (right). 


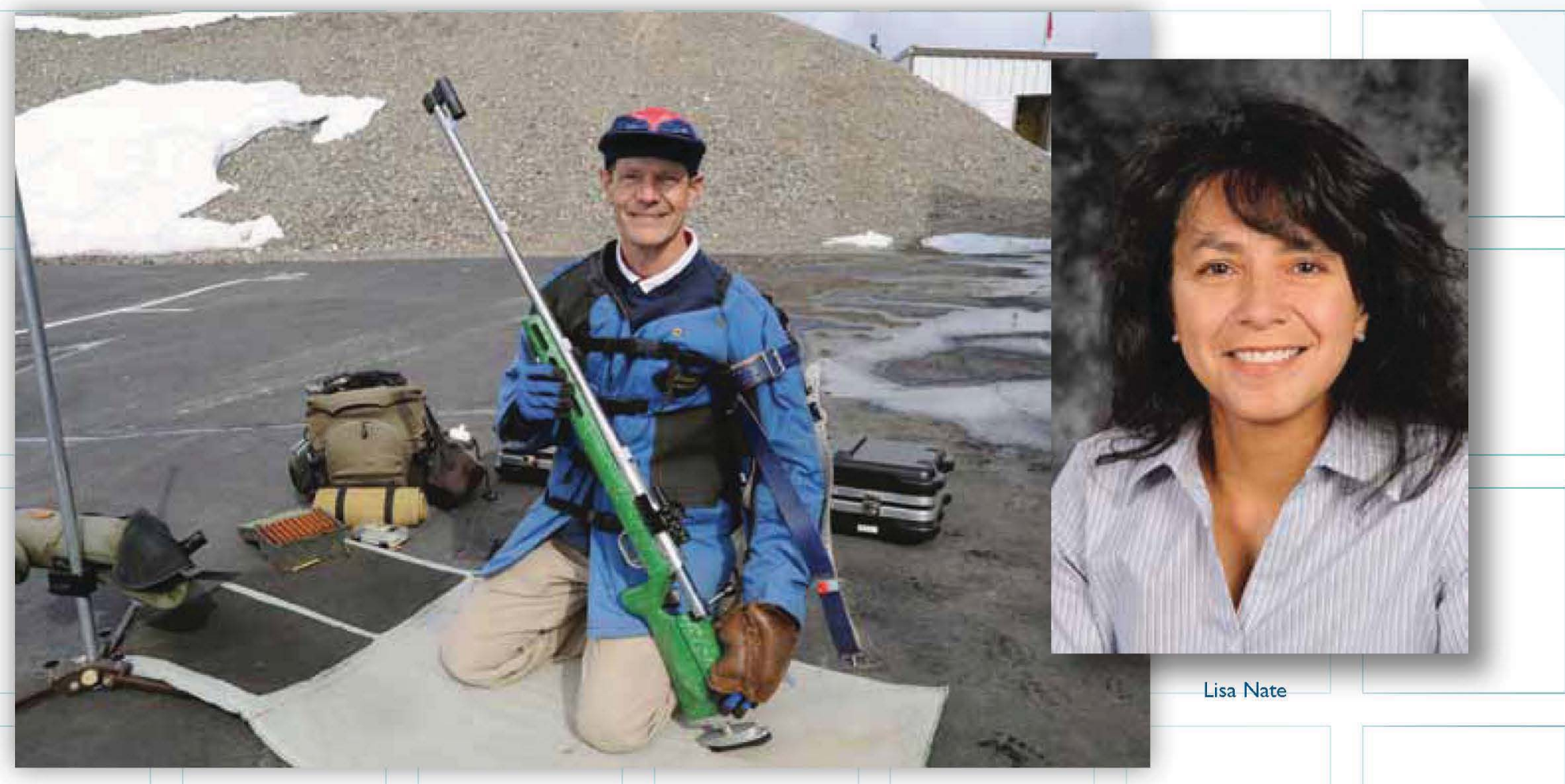

David Crandall, INL MieroSight inventor and champion marksman

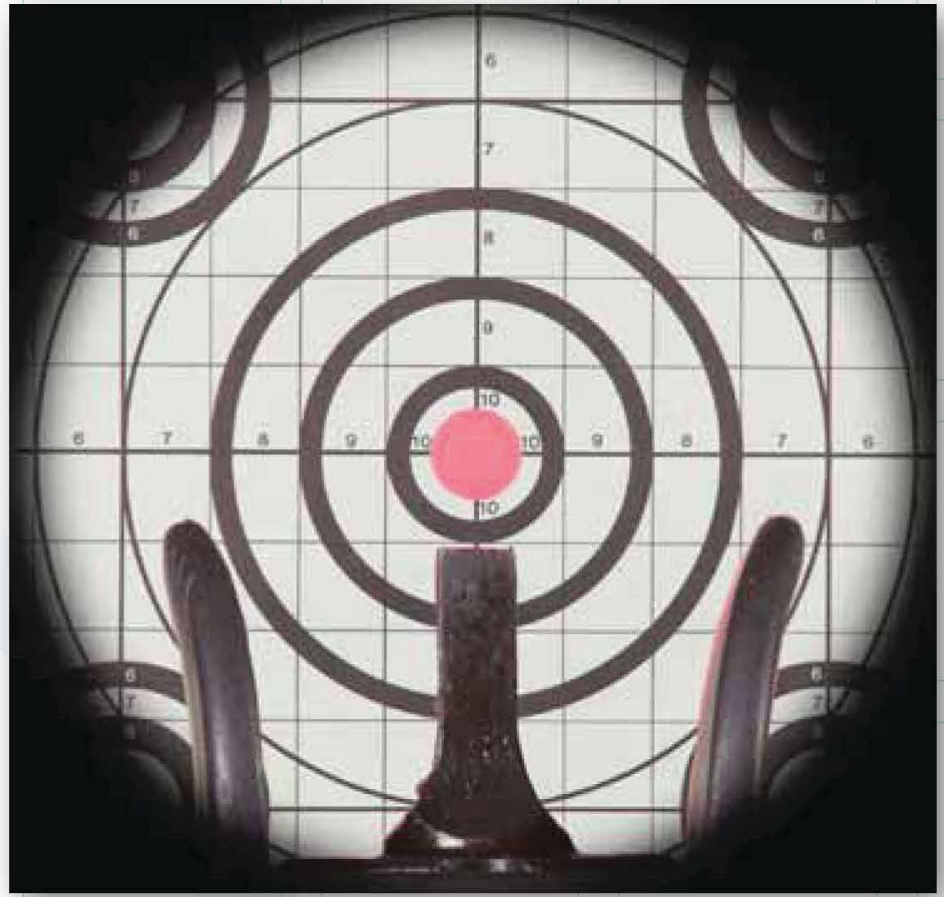

Applied Research Associates to evaluate Commercial Potential of Award-winning Robotic Intelligence Kernel

In April, Applied Research Associates (ARA) and BEA executed a evaluation license agreement allowing ARA to evaluate the commercial potential of the robotic intelligence kernel (RIK) with robotic platforms being developed for government and non-government use. RIK is a portable, reconfigurable suite of perceptual, behavioral, and cognitive capabilities that can be used across many different platforms, environments, and tasks. RIK integrates algorithms and hardware for perception; worldmodeling; adaptive communication; dynamic tasking; and behaviors for navigation, search, and detection. Providing evaluation licenses are important for building strategic relationships and advancing the commercialization of software.

\section{D Robotics, Inc. Signed a License for Non-Exclusive} Rights to Robotics Intelligent Kernel Suite

In August, a newly formed company, 5D Robotics, Inc., signed a license for non-exclusive rights to INL's RIK for commercial development. 5D Robotics is a small privately held software product and services company applying groundbreaking robotic innovations to make robots more intelligent and helpful. 


\section{Cooperative Research and}

\section{Development Agreement Highlights}

INL has a very successful Cooperative Research and Development Agreement (CRADA) program. During the past six years, INL has signed 113 CRADAs representing nearly $\$ 190$ million of research work. Ten new CRADAs were signed during FY2010 and seven modifications to existing CRADAs were negotiated. The total CRADA value during FY2010 was more than $\$ 19$ million, including about $\$ 3.5$ million of funds-in, $\$ 5$ million of in-kind contributions from participants, and slightly more than $\$ 10.7$ million in government contributions.

A CRADA may be as short as a period of months or may extend several years depending on the objectives of the collaboration. The number of transactions and the corresponding resource commitments vary considerably from year to year based on the technologies available at INL, the readiness of participants to invest in collaborations, and INL's ability to identify the right participants and negotiate satisfactory business relationships.

\section{Lightbridge Corporation:}

\section{Evaluate Alternative Nuclear Fuel Cycles}

Lightbridge requested DOE's leading nuclear laboratory, INL, to perform an independent assessment of the technical feasibility of the thorium fuel cycle in the U.S. Lightbridge's mission is to establish a new standard in global nuclear power generation, based on a core philosophy of transparency, non-proliferation, safety, and operational excellence. Study results will be compared to the uranium fuel cycle, the current actinide global commercial reactor choice. The study will review the following potential benefits: less expensive, safer, and more environmentally friendly energy. Dec. 2009
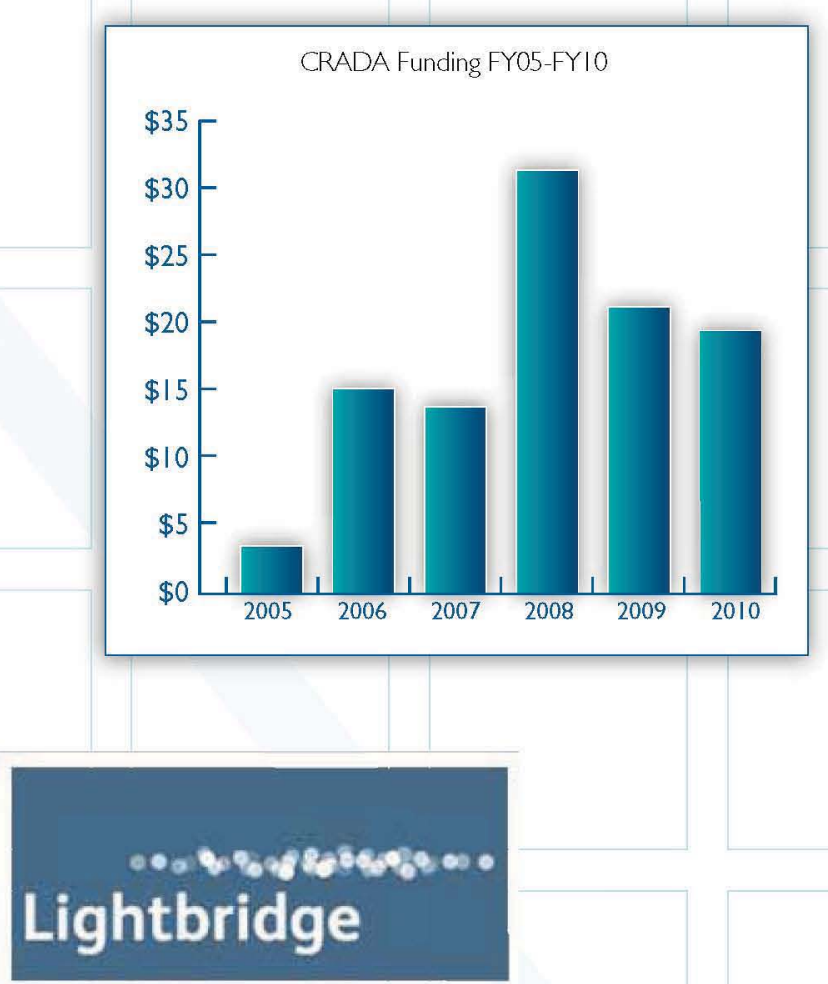

A list of the CRADAs is below, followed by a short summary of selected agreements.

\begin{tabular}{|c|c|}
\hline CRADA Partner & Technology \\
\hline $\begin{array}{l}\text { Lightbridge Corporation } \\
\text { (formerly Thorium Power LLC) }\end{array}$ & Evaluate Alternative Nuclear Fuel Cycles \\
\hline POET, LLC & $\begin{array}{l}\text { Barriers to Developing Sustainable Supply of Lignocellusic } \\
\text { Feedstock for Production of Biofuels }\end{array}$ \\
\hline EPRI & Advanced Materials to the Nuclear Industry \\
\hline U.S. Geothermal & $\begin{array}{l}\text { Develop and Demonstrate Reactive Geothermal } \\
\text { Tracers and Computer Modeling to Increase } \\
\text { Geothermal Production }\end{array}$ \\
\hline Ford Motor Company & Testing and Evaluation of Plug-in Electric Vehicles \\
\hline Shell Global Solutions, Inc. & Evaluate Biomass Feedstock Supply Systems \\
\hline NuScale Power Inc., and Designs GSE Power Systems & Investigate the Development of Multi-Module SMR \\
\hline EPRI & Studying Crack Growth Rates of Alloys X-750 and XM- I9 \\
\hline EPCO Holdings, Inc., and CoreTrace Corporation & $\begin{array}{l}\text { Whitelisting Cyber Security Assessment to Advance } \\
\text { Protection of Industrial Control Systems }\end{array}$ \\
\hline Cumming Investment Company & $\begin{array}{l}\text { Evaluate Economical Conversion of Synthesis Gas } \\
\text { to Jet Fuels }\end{array}$ \\
\hline
\end{tabular}




\section{POET, LLC: Barriers to Developing Sustainable Supply of} Lignocellusic Feedstock for Production of Biofuels

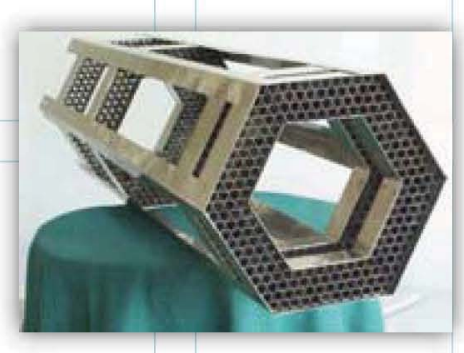

POET, LLC develops processes for cellulosic ethanol conversion processes, owns the BPX process that converts starch to ethanol without heat, and produces more than one billion gallons of ethanol annually. They developed the BFRAC process to separate corn into three major components.

Recognizing INL's leadership in feedstock process research, POET, LLC contracted with INL to study the collection and use of corncobs as a feedstock for its cellulosic ethanol process. The proposed work studies two feedstock designs: (1) a conventional loose cob system and (2) a pioneer system based on direct-baling of cob in an innovative large square bale format. The research will examine the critical biomass stability issues of spontaneous combustion, dry matter loss, and compositional degradation during biomass storage in the designs. Feb. 2010

\section{EPRI:Advanced Materials to the Nuclear Industry}

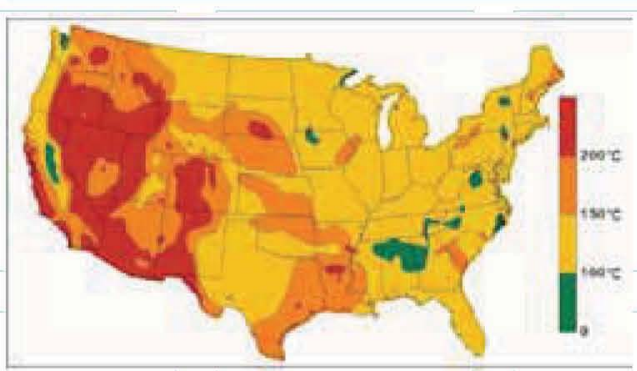

Electric Power

Research Institute and INL negotiated an agreement for experiments to obtain data on anomalous growth of zirconium alloys under certain reactor operating conditions. This

experiment will provide data on zirconium alloy growth rates as a function of hydrogen content and investigate a postulated hydrogen-assisted irradiation growth rate mechanism that may be operative in zirconium alloys. It is associated with BWR channel bowing. March 2010

\section{U.S. Geothermal: Develop and Demonstrate Reactive} Geothermal Tracers and Computer Modeling to Increase Geothermal Production

U.S. Geothermal signed a CRADA to pursue research in developing and demonstrating reactive geothermal tracers, and a computer modeling program designed to help set up and interpret results from field-scale geothermal tracer tests. The tracers and modeling program may have commercial application in tracking thermal fronts and to reservoir sizing for use in producing geothermal energy. If commercialized, this product could help advance the use of geothermal resources. The work is being conducted by the Energy and Environmental Directorate - Energy Resource Recovery Program. April 2010

\section{Shell Global Solutions, Inc.: Evaluate Biomass} Feedstock Supply Systems

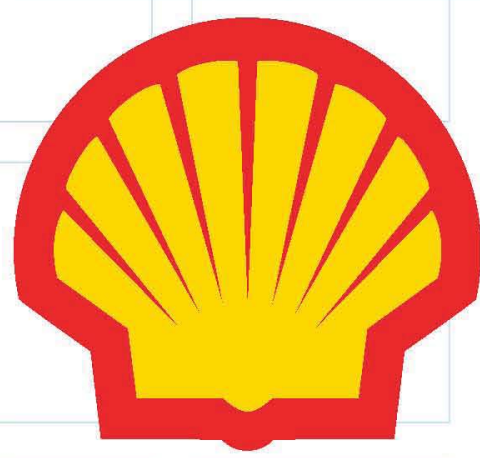

SHELL signed a CRADA to strategically evaluate the feeding and feedstock de-risking of biomass conversion platforms through the testing of several components and the integrated modeling of the biomass feedstock supply system. Researchers will determine the cost and performance impact of various technologies on supply system

designs, as well as biochemical and thermochemical conversion platforms. This research also explores enabling communities to generate their own fuel from biomass, which would provide environmentally sustainable U.S. energy security and economic stimulus. May 2010

\section{Ford Motor Company: Testing and Evaluation of Plug-in Electric Vehicles}

Ford Motor Company agreed to use INL's unique testing capabilities that will pursue joint testing and evaluation of plug-in electric vehicles (PHEV) in support of DOE's ongoing efforts to reduce vehicle consumption of petroleum and promote PHEV technology development. The research is being conducted by the Energy and Environmental Directorate Transportation Program to bring plug-in hybrid technology to market, which can provide energy independence, increase fuel efficiency, reduce greenhouse gas emissions, reduce operating costs, and eliminate range anxiety. April 2010

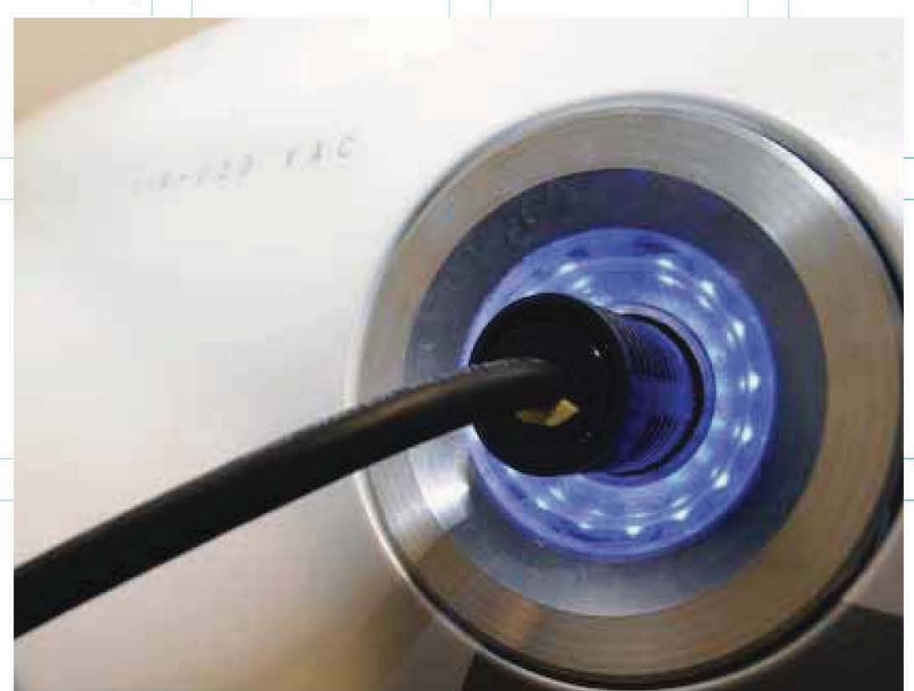




\section{NuScale Power Inc., and GSE Power Systems: Investigate the Development of Multi-Module SMR Designs}

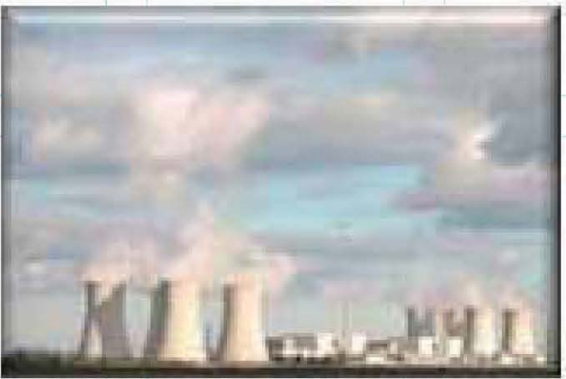

screens for multiple modules, and testing for operator comprehension. This research is based on the NuScale reactor design, but the results will be generic and applicable to any multi-module SMR design. SMRs, such as NuScale's 125 MWe units, offer an alternative to communities or industrial complexes requiring smaller incremental additions to the electric grid. This CRADA contributes to the advancement of nuclear energy by benchmarking instrumentation and controls in anticipation of the revitalization of the nation's nuclear power industry. In the future, other SMR suppliers may join in this research effort and may possibly be included in future DOEapproved modifications to this CRADA. June 2010
EPRI: Studying Crack Growth

Rates of Alloys X-750 and XM-19

Power Inc., a

(SMR) supplier, and

GSE Power Systems,

Inc. a simulator

vendor, have signed

an agreement for INL

to investigate the

development of meth-

ods for displaying

information, develop-

ing and configuring

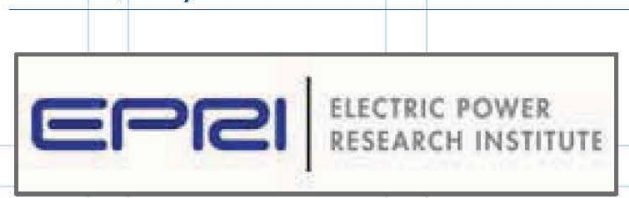

Electric Power

Research Institute

executed a CRADA

for Phase 2 of a

program designed

to provide (1)

quantitative data on crack growth rates of alloys X-750 and XM-19, (2) material for microstructural examination, and (3) material for subsequent detailed investigation of crack growth mechanisms. The scope of work for Phase 2 of this project consists of design and fabrication of an Advanced Test Reactor (ATR) loop 2A test train and sample holders, experiment neutronic and thermal analysis, and experiment specific safety analysis associated with the EPRI test train.

The ATR National Scientific User Facility (NSUF), established in April 2007 , is designed to facilitate and support world-class nuclear R\&D for academia, the commercial nuclear power industry, other national laboratories, and international organizations engaged in nuclear power R\&D. EPRI's use of the ATR NSUF promotes cooperative research with industry by executing research programs that address issues that have wide applicability across the nuclear industry. June 2010

\section{Cumming Investment Company: Evaluate Economical Conversion of Synthesis Gas to Jet Fuels}

Cumming Investment Company signed a CRADA to develop a dimethyl ether to middle distillates process, and will provide economical conversion of synthesis gas to diesel and jet fuels. The research will analyze preliminary modeling with initial economic feasibility results and compare against published competing technologies of synthesis gas to middle distillates. This agreement enables communities to generate their own fuel from biomass, providing environmentally sustainable U.S. energy security and economic stimulus. Sep. 2010 


\section{Work For Others}

INL's Work for Others (WFO) program allows other agencies and the private sector to leverage INL capabilities and intellectual knowledge on a full cost recovery basis. Since 2005, WFO has negotiated 309 projects that represent nearly $\$ 1.8$ billion of work.

During the past two years, process improvement efforts have achieved significant efficiencies in WFO, reducing time of response and speeding projects into action. In FY2010, 42 new federal and non-federal projects were added to the program, accounting for nearly $\$ 180$ million.

Some of INL's significant WFO projects include:

Central Research Institute of Electric Power Industry: Advance Safety and Monitoring of Nuclear Waste Storage Canisters

Central Research Institute of Electric Power Industry has contracted research into the possible deterioration of nuclear waste storage canisters stored in the concrete casks.

The research will review stress corrosion cracking phenomena in a salty air environment and evaluate the potential use of INL's Yucca Mountain Waste Package Closure System (WPCS) for spent nuclear fuel and high-level waste. INL's system includes welding the lids in place by remote control, nondestructive examination of welds and stress mitigation by laser peening, and a burnishing process. June 2010

Nuclear Fuel Industries (NFI):

Cold Hex Block Specimen Testing Assistance

INL will perform Transmission Electron Microscope (TEM) microstructural characterization and shear punch mechanical testing on one 304 stainless steel un-irradiated hex block from several depths to determine baseline depth-dependent starting properties of a typical hex block. This research project involves un-irradiated stainless steel and not fuel. For DOE, this research will advance a nondestructive technique to measure void swelling in the internal components of fast nuclear reactors and develop analytical tools to predict distortion by void swelling and irradiation creep in thick structural components operating in significant gradients of temperature and neutron flux spectral. This research is important to both the Advanced Fuel Cycle Initiative (fast reactors) and the Light Water Reactor Sustainability Program. Dec 2009

\section{ExonMobill.}

\section{ExxonMobil:}

\section{Oil Shale Fracturing Process}

Exxon Mobil Corporation has requested that INL researchers investigate the use of its physi-

cally based numerical model to simulate the occurrence and propagation of fractures during the Electrofrac TM Process. INL's modeling capability is unique and proprietary and not available to the private sector. The research will be conducted in two phases: (1) investigation of isothermal systems focusing on the coupling between fluid generation, expulsion, and fracturing, and (2) identification of the types and amounts of contaminants that can be leached from spent oil shale as a function of retorting temperature. May 2010

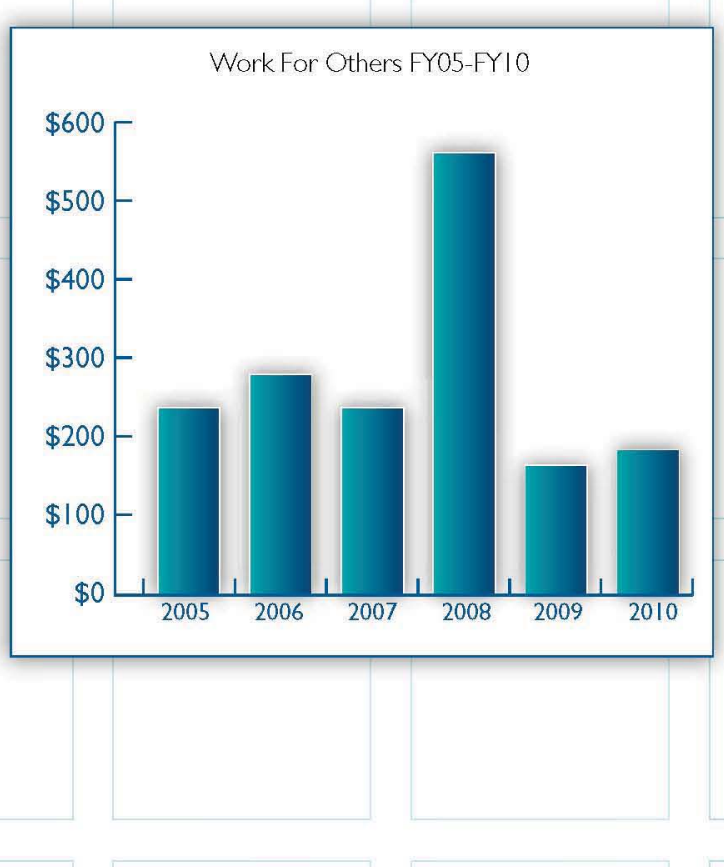

\section{Raytheon Company, Integrated \\ Defense Systems: Integrated Stand-off Inspection System}

Raytheon Company, Integrated Defense Systems signed an agreement for INL support on a Raytheon-led team effort to rapidly develop the Integrated Standoff Inspection System. ISIS is being developed for a military customer in response to a call for advanced detector and nuclear forensics $R \& D$. The system is intended to be a fully integrated detection system comprised of components at Technical Readiness Level (TRL) 4 or greater. The overall development program is expected to occur in four phases over two years. July 2010

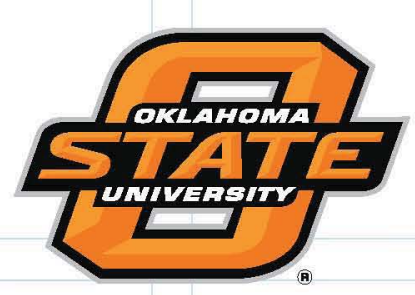

Oklahoma State University: Sustainable Feedstock Production Supply Systems Cellulosic Biorefinery Industries

Oklahoma State University and INL will deploy and assess an integrated system for supplying energy crops in three different geographic locations. Feedstock supply system investigations will follow a schedule for harvesting, storage, and sampling. The feedstock supply system evaluations will primarily consist of harvesting, collection, storage, preprocessing, biomass characterization, and data collection/analyses. Sep. 2010 
Russian Research Institute for Nuclear Power Plant Operations: Support for a Training Workshop on Advanced Time-Dependent Reliability Data Analysis

The Russian Research Institute for Nuclear Power Plant Operations has requested that INL conduct a five-day workshop to be presented in Moscow, Russia on the methods and approaches for advanced timedependent reliability data analysis. These methods can be used in nuclear power plants to evaluate the effects of ageing and provide insights into ageing management. Sep. 2010

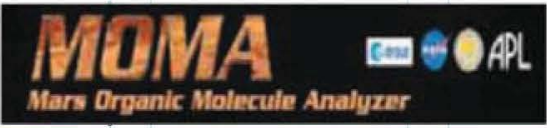

John Hopkins

University: Alternative

Ion Inlet Design to the Mars Organic Molecule Analyzer (MOMA)

Johns Hopkins University (JHU) requested services from BEA to design an alternative ion inlet for the Mars Organic Molecule Analyzer (MOMA) instrument being designed and built by JHU. MOMA is a multisource mass spectrometer that looks for chemical traces of potential life on Mars on European Space Agency's (ESA) ExoMars mission. The INL has expertise in modeling ion trajectories in viscous and vacuum environments and has experience with the type of samples that MOMA will need to be tested on prior to launch. Oct. 2009

\section{Edenspace: Economic Impact of Ensilement of Biomass}

In support of the DOE, Energy Efficiency and Renewable Energy, Office of the Biomass Program's cellulosic ethanol R\&D portfolio, Edenspace Systems Corporation has been awarded an Small Business Innovation Research (SBIR) grant to perform R\&D on lignocellulosic biomass that reduces the severity of the pretreatment process for converting lignocellulosic biomass to ethanol. The INL Bioenergy Program is a contributor to the project with its expertise in feedstock supply system logistics and cost analysis and will perform laboratory analysis of ensiled biomass in coordination with Edenspace field ensiling tasks. Chemical analyses will include organic acid production, $\mathrm{pH}$, and compositional analyses and will measure ensiling pretreatment. Nov. 2009

\section{Raytheon Company: IRAD Active Interrogation Support}

Many of today's active interrogation technologies provide sub-par support for the detection of contraband. Raytheon has asked the INL to provide research and support in the area of active interrogation systems to help eliminate the need for time consuming manual inspections. Dec. 2009

GSI Environmental, Inc.: Validation of New Tools to Better Manager Vapor Intrusion Liability

The WFO agreement with GSI Environmental, Inc. will demonstrate and validate a suite of investigation tools that will provide the U.S. Air Force with a scientifically defensible method to: (1) discriminate between indoor and subsurface sources of Volatile Organic Compounds (VOC) in buildings, and (2) document biotic and abiotic destructive processes occurring in the vadose zone that prevent/minimize vapor intrusion impacts.

INL has developed a unique capability to measure the potential and directly assess the enzymatic activities of specific micro-organisms. Data from these unique tools will be compared with other more standardized techniques to validate their use for evaluating unsaturated subsurface environments. Together these tools provide a robust evaluation of biodegradation potentially critical for environmental restoration. Mar 2010

Control Point Corporation: Receives INL Consulting Services to Support the Brigade Combat Team Modernization (BCTM) Active Protection System (APS)

Control Point Corporation has signed an agreement to obtain INL subject matter expertise and consulting services in the areas of system

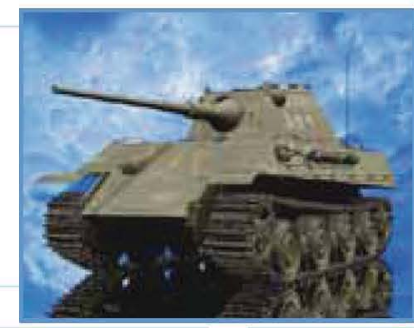
engineering, testing, and modeling and simulation to assist in the Brigade Combat Team Modernization (BCTM) Active Protection System (APS) Technology Transition Plan. The Technology Transition Plan is intended to further develop and document the maturity of the current APS so that it may be offered to the Ground Combat Vehicle (GCV) program as one option for an APS solution in the FY2011 time frame. The project also will develop other software tools applicable to other system engineering, testing, and modeling and simulation projects. June 2010

INIS: Modifies Agreements for Continued Production of Life Saving Medical Isotopes

International Isotopes Inc. (INIS) executed three modifications for continued production of medical isotopes that are used in for cancer treatments, nuclear medicine reference and calibration standards, medical teletherapy products, specialty gases and uranium conversion services and transportation services. March 2010

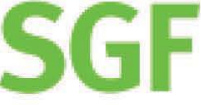

Sweet Green Fields, LLC
Sweet Green Fields: Evaluation of Process Development Unit Drying Module

Sweet Green Fields has contracted with INL to use its Process Demonstration Unit (PDU) in to demonstrate and evaluate the efficiency and operational costs of its proprietary methods for preprocessing and drying biorenewable feedstock. The SGF drying module is based on a standard rotary kiln-type drying technology and is capable of processing up to 10,000 pounds/hour of materials with $50 \%$ moisture down to $10 \%$. The PDU drying module is unique in that given the rated capacity, the design allows it to be truck transported to and operated in remote locations. Aug. 2010

\section{Lynntech, Inc.: Conultative Services on Nonthermal Plasma} Synthesis of Biofuel from Home Based Waste

Lynntech Inc. has contracted for consultative support in evaluation of their non-thermal plasma process for producing biofuels from homebased biorenewable feedstock. Sep. 2010 


\section{Technology-Based Economic Development Highlights}

With a $\$ 3.5$ billion total economic impact within Idaho (Boise State University study, 2010), INL's technology-based economic development (TBED) efforts are designed to enhance the development of a nurturing entrepreneurial climate, leverage INL capabilities, and foster the transfer of intellectual property to the private sector. This strategic approach focuses on two fronts:

1) Application of technology in traditional industries to produce a more robust, high-technology business sector, and

2) Development of innovative enterprises for expanding existing companies, new ideas, and new enterprises with high-technology visions and capabilities. Forming effective partnerships within the region is most important to wisely investing the $\$ 4.5$ million of education and economic development grants that INL provides each year.

\section{Leveraging Economic Development Partnerships}

A key to INL's TBED strategy is continuing to develop effective partnerships among geographically dispersed organizations to ensure thorough regional coverage and foster organizations that have important skills and technical acumen to be shared among entrepreneurs and emerging businesses. Making key technical and business skills available to those who can create well-paying jobs in the expanding high-technology business sector is important to the future. Linking those with potential to technical capabilities, business skills and capital advances the business climate for economic expansion and job creation.

INL works with and sponsors several partners and activities to enhance an entrepreneurial environment, including:

Idaho TechConnect (TechConnect) is Idaho's first and only publicprivate, non-profit organization focused on turning Idaho's ideas into Idaho's businesses. Established with Tech nology Deployment support, INL has partnered with TechConnect through a Master Task Agreement to support TBED initiatives. This organization and INL's close working relationship with it have helped extend the reach of INL and leverage limited resources across the state and the Northwest region.

TechConnect's results are positive and increasing in impact. During FY2010, assistance or referral was provided to 412 technology-based companies and individuals. Of this assistance, $292(71 \%)$ were new clients while $119(29 \%)$ were ongoing from FY2008. Of the 292 new clients, $146(55 \%)$ became ongoing clients and 131 (45\%) were referred to other services or organizations. Regional reports captured employment data for 156 of the 265 ongoing clients. These companies employ 936 people. Using the average for those companies that reported data, the calculated total employment for all 412 companies assisted through this quarter end would be 2,472 . Using average wage figures for these business segments $(\$ 60,000)$, these companies paid nearly $\$ 152$ million in wages, and the employees paid just over $\$ 8$ million in Idaho income taxes. The following three companies are examples of the program:

- Beckmer Products is a company dedicated to alternative, handsfree solutions to data entry that challenges the dental and medical industry. An emerging, custom electronic device company, Beckmer specializes in developing and marketing foot-operated data input devices for the worldwide dental industry. Beckmer has accumulated over three years of experience developing and introducing its first application for dental offices and schools across the country and across the world. In addition, Beckmer has begun work on its first medical-specific device.

- Io Dupont is a company that develops high-end technology products to optimize performance in the intended application. Their flagship product, Power Cordz, is a synthetic fiber cable system designed to address the problems of steel control cables currently used on bicycles. Steel cables are prone to stretching and corroding, and they add unnecessary weight. Years of research, testing, and teaming with the best synthetic fiber experts yielded Power Cordz, a superior fiber control cord that does not corrode and is $75 \%$ lighter than the current standard. Power Cordz are sold worldwide through multiple distribution chains. Io DuPont is currently working on a continuously variable transmission (CVT) that is expected to revolutionize the bicycle and simultaneously impact multiple industries, including wind, electric cars, scooters, and dam generators among several others.

- Blackhawk Energy is a renewable energy research and design company dedicated to improving wind energy technology. The TR10 Tilt Rotor Vertical Axis Wind Turbine with Articulating Rotor (VAWT/AR) is their first Wind Turbine. It is designed to provide clean power options, reduce stress on existing grid systems, compliment photovoltaic solar systems, distribute power (point of use) options, ease installation, lower needed maintenance, and is proven to be cost/watt competitive.

In addition to the direct assistance to individuals and companies under the Master Task Agreement, TechConnect manages five other programs focused on facilitating an entrepreneurial culture; increasing industry, university, and laboratory collaboration; encouraging early stage financing; and facilitating the infrastructure for an entrepreneurial culture. Those programs are as follows:

Kickstand of Idaho continues to grow with technology networking organizations in four Idaho locations and interest growing in other locales. INL co-sponsored the establishment of this networking effort in 2008 to increase awareness in a series of Idaho technology and innovation initiatives. More than 2,034 individuals have participated since Kickstand began. Speakers from INL, laboratory spinout companies, regional entrepreneurs, INL researchers with commercialized technologies, and other business people with a variety of skills add to the rich mosaic offered in this business network association.

During FY2010, INL provided financial support and coordinated other sponsors for three Kickstand chapters (Moscow, Twin Falls, and Idaho Falls). The total attendance for the three chapters grew to 1,023, with average monthly attendance at about 24 for Moscow, 32 for Idaho Falls, and 28 for Twin Falls. 
Science On Tap and Science Café are two special technology forums that remain strong network affiliates with INL and TechConnect. INL regularly provides speakers on technology development and commercialization in areas such as energy research (hybrid energy systems, biomass, electric vehicles, etc), intellectual property management, technical assistance availability, and other topics.

\section{Idaho's TechLaunch 7.0}

was held in May with eight regional companies presenting their technologies after winning their regional competitions. The quality of presentations continues to improve, and the number of companies competing across the region this year reached 19 .

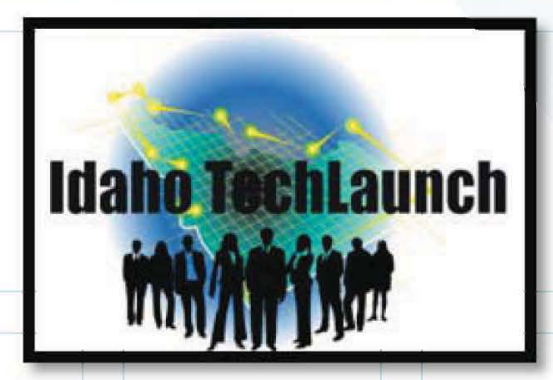
In addition, six business plan teams from regional universities competed for scholarships provided by INL. Students participated from Brigham Young University (BYU)-Idaho, University of Idaho, Boise State University, Idaho State University, Washington State University, and the Idaho Entrepreneurial Center (E-Center). Winners of the company and student business plan competitions carried home more than $\$ 20,000$ in cash and services. Participation continues to grow each year, and in FY2010 more than 225 participants attended the two day event. During the past seven years, 53 companies have participated in this event and 40 remain in business. These companies have garnered more than $\$ 35$ million in early stage $R \& D$ investment funding.

I2M Program is a new education effort launched in 2009 and revamped in 2010 with student teams from University of Idaho, Boise State University, Idaho State University, Washington State University, and BYUIdaho participating. I2M offers real-world experience for student research teams to produce a current technology assessment that students can add to their personal business portfolios. INL benefits with an assessment as to whether the technology or idea has potential to be a start-up company. Results from this program will be presented at Tech-Launch 8.0.

Entrepreneurial Workshops. Working with Idaho TechConnect, several skill-building entrepreneurial workshops were organized during FY2010. Workshops were held at the University of Idaho, INL's Center for Advanced Energy Studies (CAES), and Boise State University. These workshops were attended by 73 faculty researchers that are affiliated with CAES. Participants were exposed to key skills such as developing wellwritten business plans, capital investments basics, developing successful investor presentations, and much more. The workshops also include some discussion about federal funding, including Small Business Innovation Research (SBIR) and Small Business Technology Transfer (STTR).

Coordinating Federal Assistance for Companies. TechConnect, along with the INL provides ongoing counseling, mentoring, and assistance to entrepreneurs and companies for federal funding opportunities, including SBIR/STTR programs. This assistance includes, but is not limited to, SBIR/STTR, Broad Agency Announcements (BAA), federal and large company procurement, Request for Information (RFI), Funding Opportunity Availability (FOA) and federal appropriations process and contacts. Often, these efforts result in additional technical assistance work for INL, including CRADAs and Work For Others.

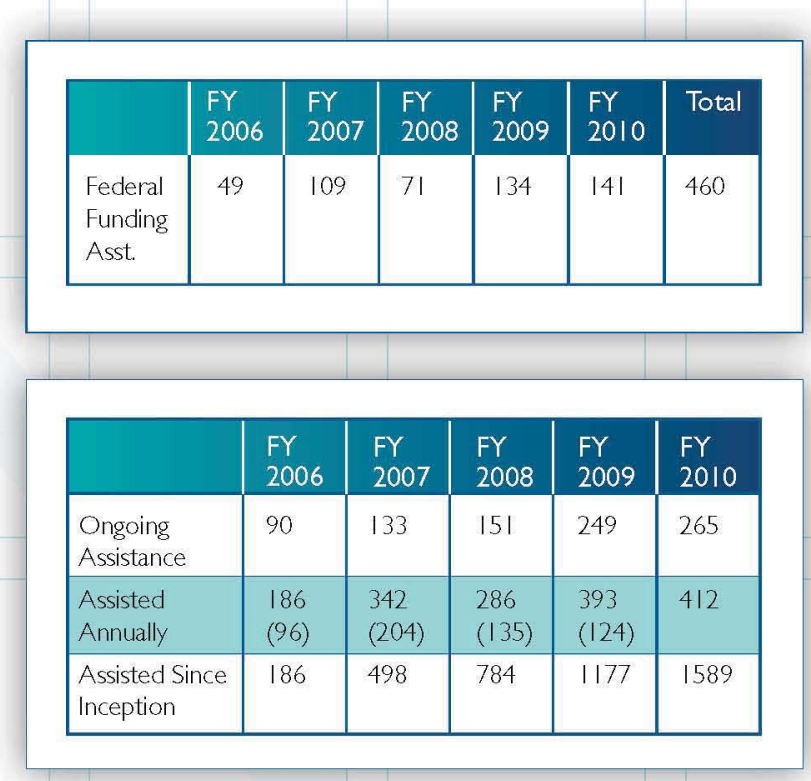

During FY2010, 141 companies and individuals received assistance related to obtaining Federal Financial Assistance. INL also teamed with the State of Idaho in coordinating regional federal funding workshops. The workshops were held in Moscow, Post Falls, Boise, and Idaho Falls with close to 50 businesses and individuals in attendance. Eight companies have submitted SBIR proposals to federal agencies and three more are preparing submission. Five companies have received Phase I awards during the year and three have submitted Phase II proposals. The table above shows results since the inception of Idaho Tech Connect.

Idaho Economic Development Association (IEDA) is a trade association of economic development professionals and affiliated entities whose purpose is to enhance and elevate the practice of economic development and to promote sustainable business growth for Idaho's economic vitality and increased standard of living. INL provided financial support, in-kind services, speakers and training for approximately 300 participants during the quarterly training.

Idaho Rural Partnership (IRP) is a major public-private organization dedicated to improving economic and social conditions in this large, rural state. INL has worked to advance science, technology, engineering, and mathematics (STEM) education; business development; and entrepreneurial climate in Idaho's rural communities. This partnership is vibrant as INL works with IRP board members (state legislators, governor's representatives, congressional offices, state and federal directors, and others) and the regional representatives within the IRP organization. Business and entrepreneurial skills training have been a key pursuit during FY2010 and will remain so in the immediate future.

With these strong partners and other organizations in the region, INL has had the enhanced ability to sponsor programs and activities that have made significant impact on promoting economic development and advancing a high-technology work force in the region. Some of those activities include: 


\section{Technical Assistance Program (TAP)}

- Support for National Conferences. INL sponsored five major conferences in FY2010, including the State Science and Technology Institute National Conferences in Kansas City and Pittsburgh; the 2009 International Economic Development Council (IEDC) Annual Conference in Reno, Nevada; IEDC 2010 Federal Economic Development Forum in Washington, DC, and the Pacific Northwest Economic Development Council conference. INL Deputy Director David Hill was a keynote speaker in Reno with close to 800 participants. INL Laboratory Director John Grossenbacher spoke to the national Washington forum. A series of regional forums were also held. In addition, through INL's partnerships with regional development organizations, INL personnel participated in three national energy conferences - Renewable Energy Conference 2010, Wind Power 2010, and Solar Power International 2010. The outcome of these conferences was an increase in awareness of INL's efforts and desire to partner with technology-based businesses for economic development.

\section{- Technology Showcase with} Meridian, Idaho was a special event designed to advance the technology transfer culture in sharing INL technologies and capabilities, promote innovation, and educate researchers on technology transfer issues. Working with the Mayor of Meridian, this event sought to highlight a special collaborative effort on energy efficiency involving the City of Meridian, INL, CAES, and a contractor who had a bio-digester technology that could produce energy for the city. Brent Stacey, Director of Technology Deployment at the time, spoke to participants. A technology showcase was then held to share INL's capabilities and technology transfer efforts. More special events involving communities are anticipated for the future.

- Special Events are held periodically to encourage innovation in Idaho and to share with local business and civic leaders the commercialization opportunities that exist at INL. In September, two tours were conducted for business and civic leaders from Boise's Treasure Valley and Twin Falls' Magic Valley. The groups visited INL facilities, learned more about INL's capabilities, and discovered current and potential impact that INL has on Idaho's economy.

\section{INL Teams with Center for Advanced Energy Studies to Assist in Proposal for the DOE Innovative Ecosystem}

INL's Technology Deployment teamed with CAES and others to support a proposal on the DOE Innovative Ecosystem. Idaho Tech Connect staff led the effort to pull together a team of thirteen partners to complete and submit a proposal for a three-year Ecosystem Development Project estimated at $\$ 435,000$ per year. Partners included: INL, CAES, University of Idaho, Boise State University, Idaho State University, City of Meridian, Portas Ventures, Headwaters MB, Invest Idaho, Cyanergy, Advanced Bio-Energy Systems, Idaho State University (College of Business and Research Office), and State of Idaho Office of Energy Resources.
INL's Technical Assistance Program (TAP) works to assist job creation and enhance the entrepreneurial climate for emerging high technology enterprises. TAP's contribution to strengthening and growing technology-based economies is to offer technical assistance for up to 40 hours to provide support that is not available from the private sector (e.g., by contract INL cannot compete with the private sector). During the past six years, INL has provided support to 144 TAP projects dedicating more than 5,500 hours of technical work.

After a major effort directed at refocusing TAP during FY2009, activities during FY2010 were directed at supporting retention and expansion of high-technology businesses. This year, INL provided record support, delivering 31 technical assistance projects and more than 540 hours of assistance. Most projects were focused on solving critical technical issues for companies and organizations around the state. Normally, projects are limited to one per year per organization. The business and community organizations provided technical assistance included TerraGraphics, Boise Biologics, Meter Insulator Supply, O3Co, Manning Applied Technology, Cyanergy, The Salvation Army, Glacier National Park, Idaho Department of Water Resources, Idaho Department of Drug Policy, Idaho Department of Environmental Quality, and Idaho's Custer County Road and Bridge Department.

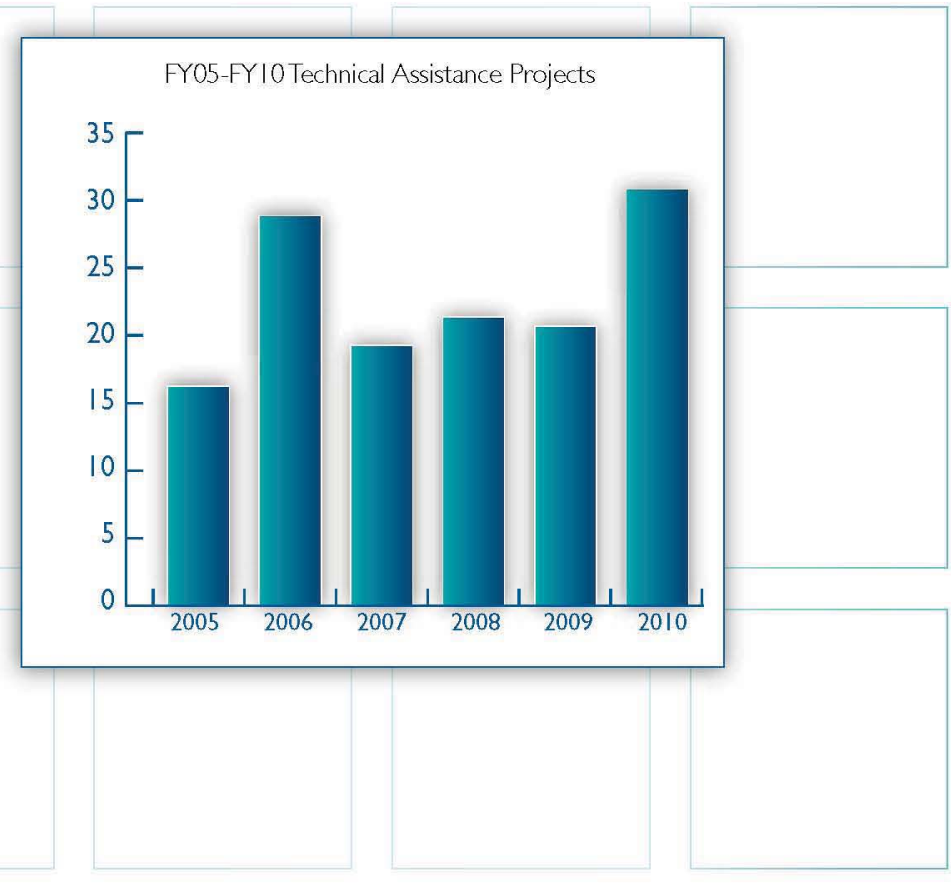



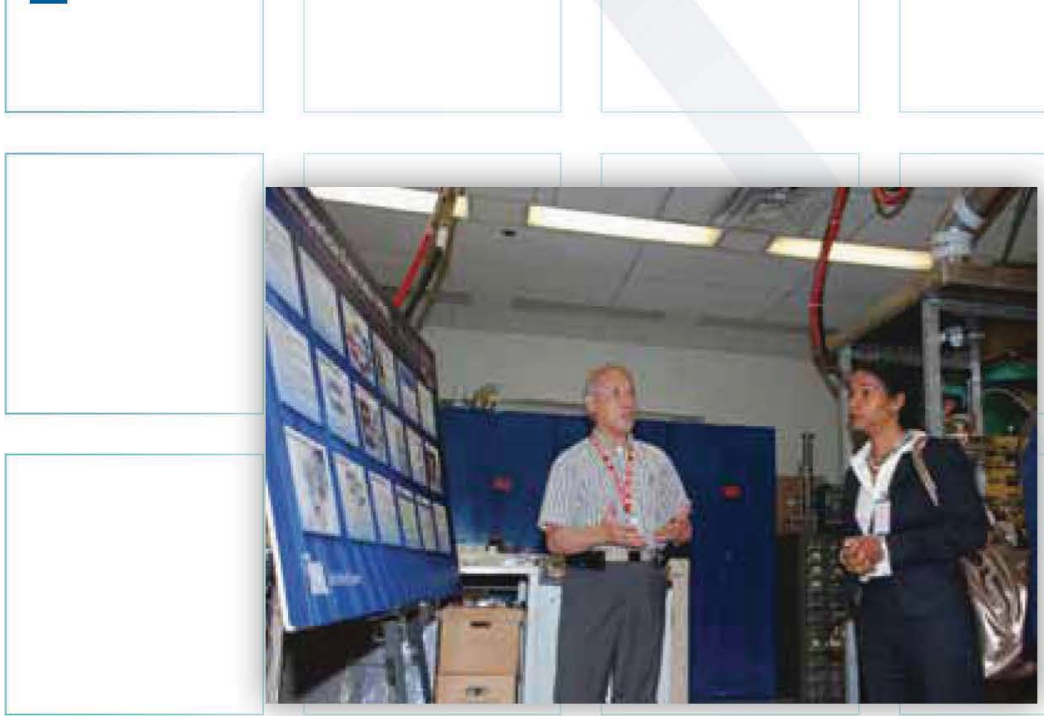

\section{Other Key Events and Successes for FY20I0}

\section{Dr. Edmonds, DOE Technology Transfer, Visits Technology Deployment and Learns of INL's Innovative Spirit}

Dr. Karina Edmonds, DOE's Technology Transfer Coordinator, visited INL on June 2, 2010, for an INL overview, an opportunity to meet INL and DOE senior leadership, and discussions with Technology Deployment staff., She met with more than 20 individual researchers in a special forum to learn about INL technologies and capabilities. A tour of selected laboratories provided insight into INL's current research, innovation, and commercialization successes. Dr. Edmonds stated that she observed an entrepreneurial spirit at INL, a legacy of innovation and intense efforts to move Technology Deployment in new strategic directions. INL also organized a media interview, which resulted in a feature

Dr. Peter Kong, inventor of the Modular Hybrid Plasma Reactor, explains nanoparticle production using his plasma reactor to Dr. Karina Edmonds from DOE Technology Transfer during her visit in June 2010. story in the Idaho Falls Post Register.

\section{Steven McMaster Named Director of Technology Deployment}

In September, Steven McMaster was named as Technology Deployment's Director to provide key strategic decisions that will enable INL's mission to deploy technology. Steve joined INL in 2010 as Technology Deployment's Senior Commercialization Manager supporting National and Homeland Security. He is a Certified Licensing Professional with significant experience managing the further development, licensing and commercialization of promising innovations.

Previously, Steve was Manager of Business Development and Technology Licensing at the Mayo Clinic in Rochester, Minnesota. He has worked with Mayo medical researchers, engineers, and software developers to advance a variety of promising medical technologies, including earlystage biotechnologies, diagnostics, medical devices, therapeutics, 3-D visualization software, CT colonography, and special-purpose processors (developed in collaboration with the Department of Defense). Steve holds juris doctorate and bachelor degrees in Business Management and Spanish from the University of Utah.

\section{INL Technology Deployment's Deputy Director Elected to Technology Transfer Working Group Executive Board}

Jason Stolworthy, Deputy Director of Technology Deployment, was elected to DOE's Technology Transfer Working Group (TTWG) Executive Board as Recording Secretary. Jason participates in the DOE technology transfer policy board and works with DOE's Technology Transfer Coordinator, Dr. Karina Edmonds. Through this position INL will contribute to policy formulation and implementation to provide national laboratories greater flexibility in partnering with industry. 


\section{INL Researchers Win Three 2010 $R \& D 100$ Awards and More}

INL researchers repeated their winning ways in 2010 with three $R \& D 100$ Award-winning technologies, replicating their performance during 2009. In fact, both years INL technologies won three of the four nominations tendered to R\&D Magazine.

The winning technologies and research teams for 2010 include:

\section{- INL's Supercritical Solid Catalyst (SSC):} Discarded and environmentally unfriendly wastes now can be converted into biodiesel fuels using a chemistry breakthrough called Supercritical Solid Catalyst or SSC. INL scientists Dan Ginosar, Bob Fox, Lucia Petkovic and Dan Wendt worked to find ways to create liquid fuels from a variety of waste streams, including municipal wastewater and food processing waste. SSC mixes

fat or oil feedstock with supercritical fluid solvents and alcohols at specific temperatures and pressures to completely dissolve the materials during a single supercritical phase. This approach overcomes a key barrier - the polar liquid phase in conventional biodiesel production, which requires multiple steps.

- INL's MicroSight: INL's MicroSight seems to transcend the laws of physics by simultaneously imaging two distinct focal planes so that a marksman can clearly focus on both the gun sight and the target. INL engineer David Crandall developed MicroSight so hunters, target shooters and military marksmen can clearly see their targets and the sights at the end of their gun barrels simultaneously. This can dramatically improve a shooter's situational awareness with better vision and safety. MicroSight is durable, incredibly small and adds less than 1/1000th of an ounce to the firearm. The MicroSight has been licensed by Apollo Optical Systems of Rochester, N.Y., a world leader in lens design and engineering.

- osgBullet: INL researchers David Muth and Joshua Koch collaborated with researchers at Ames National Laboratory and the National Energy Technology Laboratory (NETL) to develop osgBullet, which provides an open-source software toolkit that enables real-time creation and interaction with multibody dynamics simulations in a 3D graphical environment. Ames researcher Douglas McCorkle led the $R \& D 100$ submission team that included INL and NETL.
SSC converts fat, oil, and grease wastes, right, into B- 100 biodiesel using nontoxic catalysts and supercritical fluids in a single, continuous phase process. Previous industry standards were batch processing using several steps and toxic liquid chemicals that required transportation on public roads.

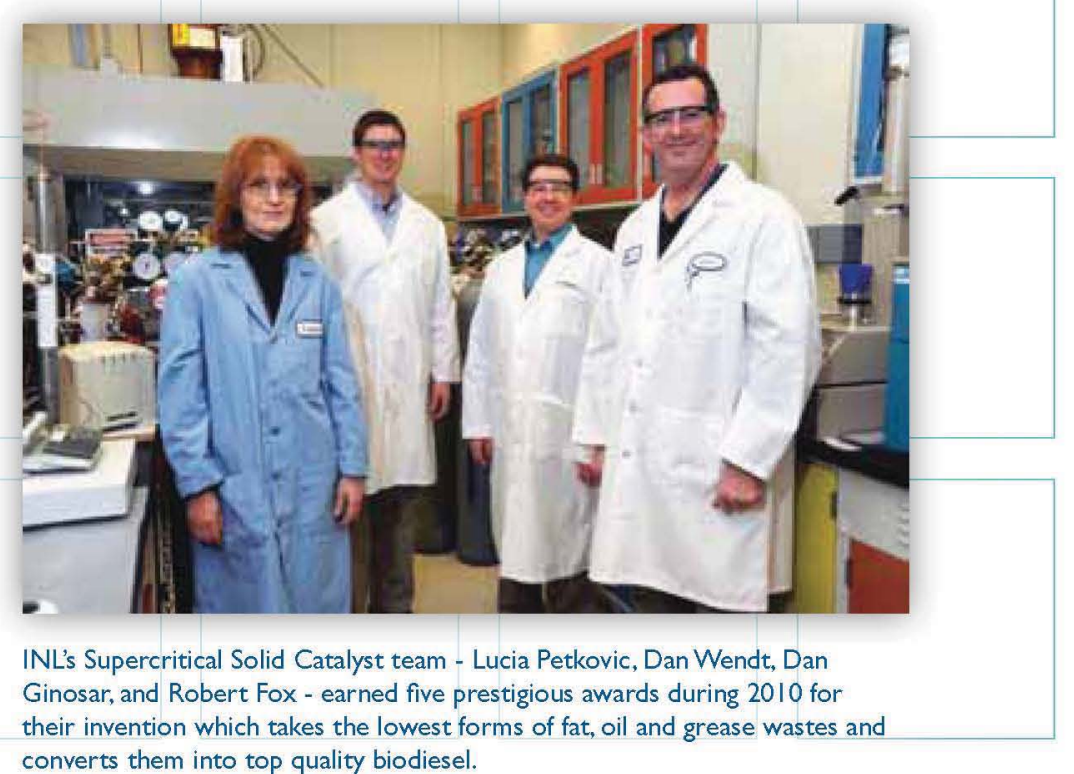
converts them into top quality biodiesel. 

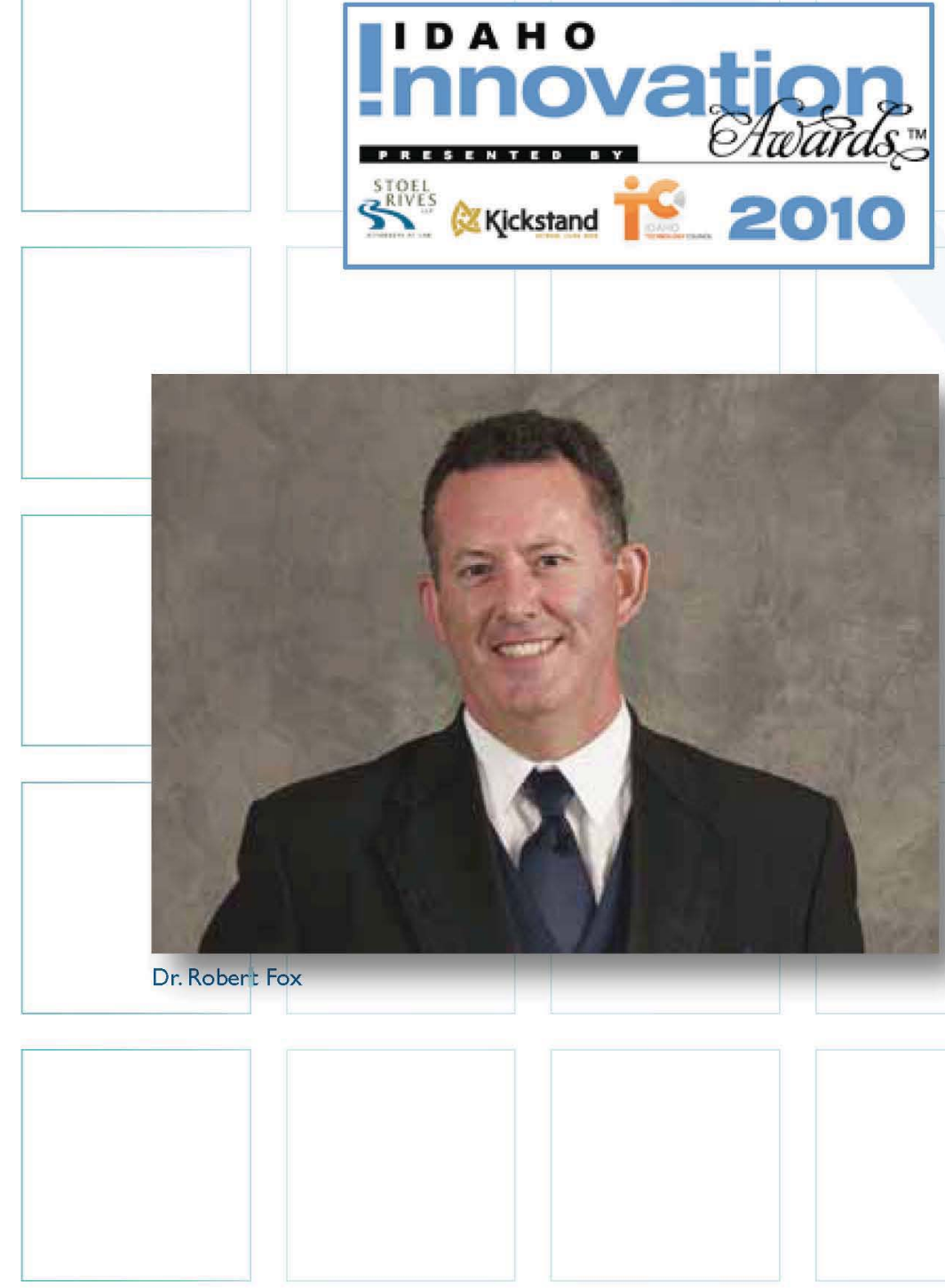

INL's SSC Wins Runner Up in Wall Street Journal Technology Innovation Awards, Finalist in Platts Global Energy Awards

INL's Supercritical Solid Catalyst (SSC) won four more awards after winning the 2010 R\&D 100 award in July. In September, SSC was selected as runner up in The Wall Street Journal Technology Innovation Awards for the energy achievement category. Immediately after that, Platts announced that SSC was selected as a finalist in the Sustainable Energy competition for their Global Energy Awards.

\section{SSC and Dr. Robert Fox Win Idaho Innovation Awards}

At the Oct. 27 dinner awards ceremony in Boise, SSC added to its trophy case by winning the Idaho Innovation Awards for Early-Stage Innovation of the Year at program.

Also, Dr. Robert V. Fox, INL's 2009 Inventor of the Year, was selected as Idaho Innovator of the Year for a 20-year career of high productivity, underscored by winning two RerD 100 awards consecutively in 2009 and 2010 .

INL Wins Federal Laboratory Consortium Far West Region Awards for Technology Transfer Efforts, Improving INL's Reputation for Deployment of Technology

Idaho National Laboratory won two Federal Laboratory Consortium Far West Regional Awards for 2010:

- Outstanding Commercialization Success: Centrifugal Contactor Separation Technology. David Meikrantz and Gary Smith received the Federal Laboratory Consortium Far West Region Award for "Outstanding Commercialization Success" in 2010 for development and licensing of the Centrifugal Contactor. Sixteen units have been deployed by Kevin Costner's company, Ocean Therapy Solutions, to clean up the BP oil spill in the Gulf of Mexico. Sixteen additional units have been ordered and are under construction by CINC Manufacturing.

- Outstanding Technology Development: Supercritical Solid Catalyst. Dr. Robert V. Fox received the Federal Laboratory Consortium Far West Region Award for "Outstanding Technology Development" in 2010 for INL's SSC technology.

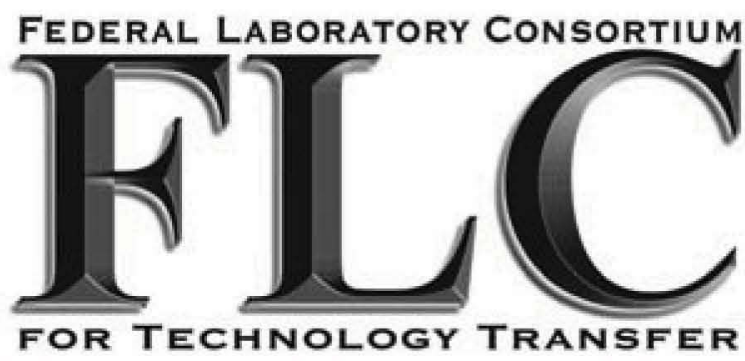



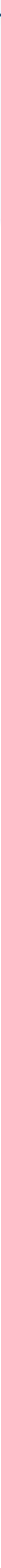

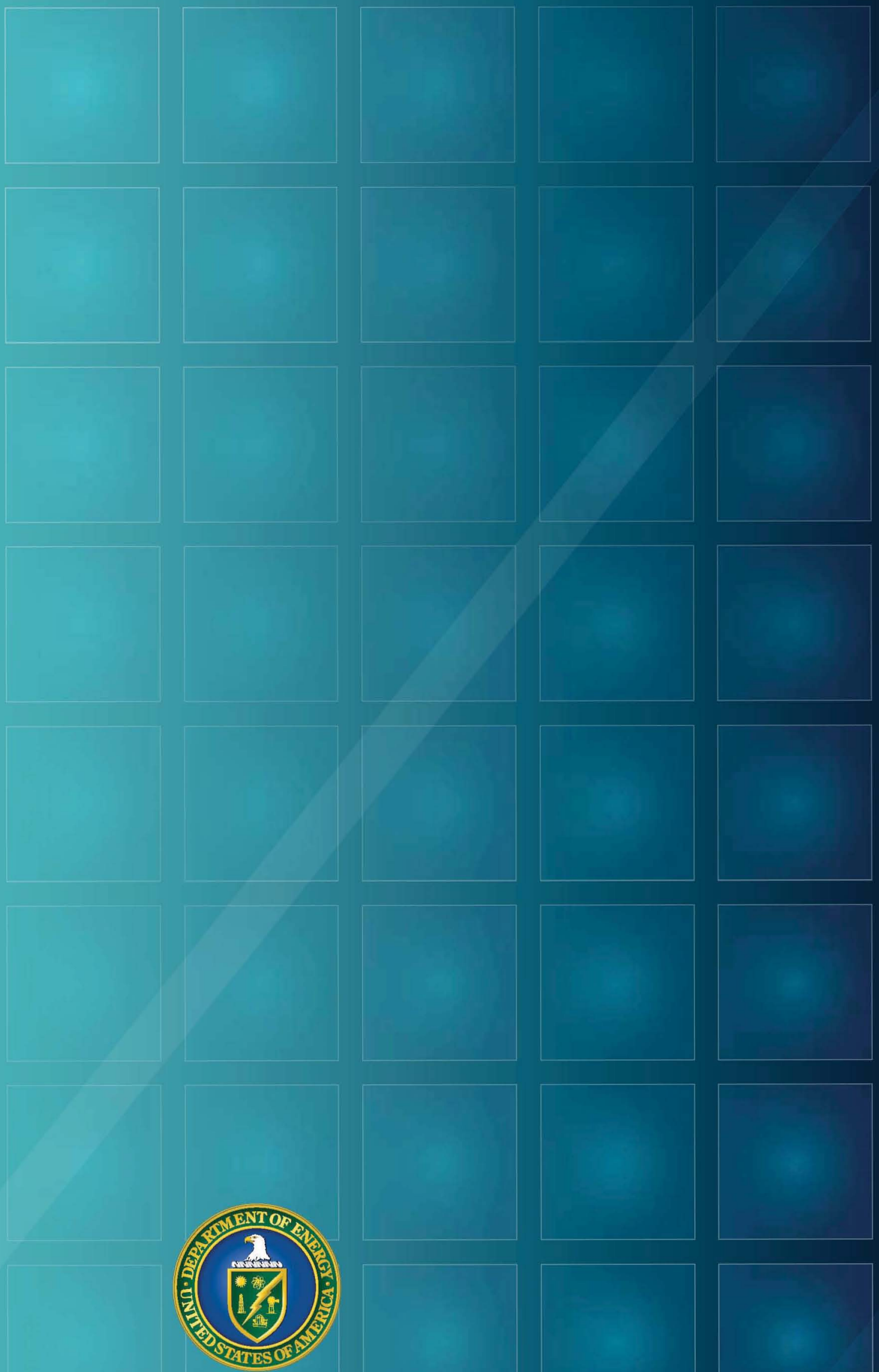

INL is one of the U.S. Department of Energy's Multiprogram national laboratories and is managed by Battelle Energy Alliance, LLC.
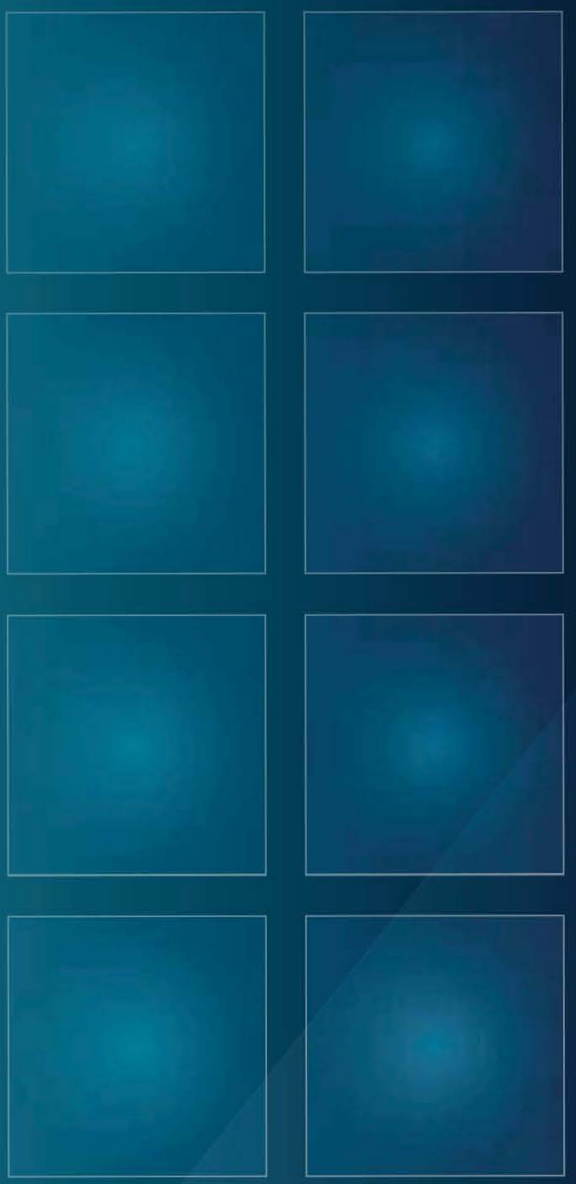

INL/EXT-10-20698 $\cdot 10-51133$ 